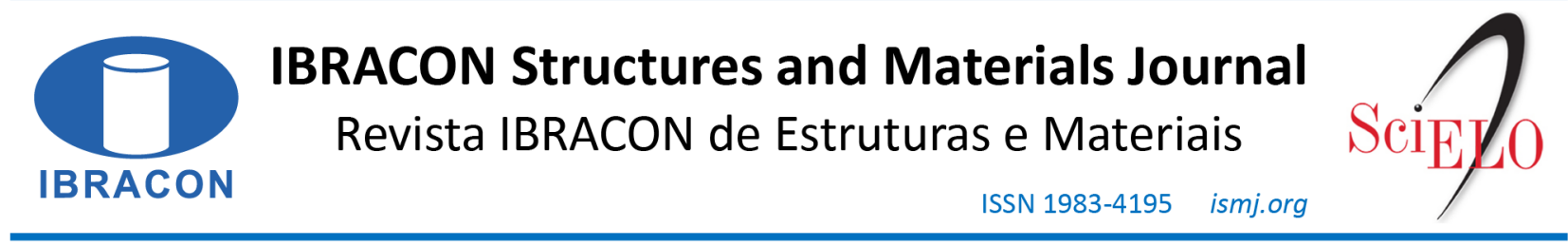

ORIGINAL ARTICLE

\title{
Probabilistic corrosion time initiation modelling in reinforced concrete structures using the BEM
}

\section{Modelagem probabilística do tempo de início da corrosão em estruturas de concreto armado usando o MEC}

\author{
Giovanni Pais Pellizzer ${ }^{\mathrm{a}}$ (D) \\ Edson Denner Leonel ${ }^{\mathrm{b}}$ (D)
}

${ }^{a}$ Universidade Federal de Mato Grosso do Sul - UFMS, Faculdade de Engenharia, Arquitetura e Geografia, Campo Grande, MS, Brasil

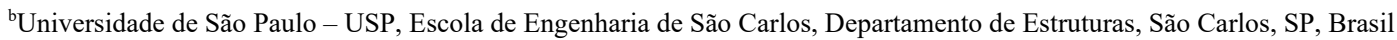

Received 28 August 2019

Accepted 30 January 2020

\begin{abstract}
The reinforcement's depassivation in reinforced concrete structures occurs when the chloride concentration at the reinforcement's interface reaches the threshold content. The depassivation phenomenon starts the propagation period, in which huge mechanical degradation processes are triggered. Moreover, it is well established that the propagation period is considerably shorter than the initiation period. Therefore, the accurate prediction of the corrosion time initiation is a major issue in structural durability domain. This study presents a transient formulation based on the Boundary Element Method (BEM) for the corrosion time initiation assessment. The diffusion fields evaluated by the BEM are utilized into a probabilistic framework, which enables the assessment of probabilistic values for corrosion time initiation. Therefore, the formulation handles properly the uncertainties in this problem, which is largely subjected to randomness. Three applications are presented. The robustness and accuracy of the proposed approach over classical analytical models are highlighted.
\end{abstract}

Keywords: chloride ingress, boundary element method, probabilistic modelling, diffusion-like transport.

\begin{abstract}
Resumo: A despassivação das armaduras em estruturas de concreto armado ocorre quando a concentração de cloretos na interface das armaduras atinge a concentração limite. O fenômeno da despassivação inicia o período de propagação, no qual enormes processos de degradação mecânica são desencadeados. Além disso, é largamente conhecido que o período de propagação é consideravelmente curto se comparado com o período de iniciação. Portanto, a precisa previsão do tempo de início da corrosão é um tema de importância maior no domínio da durabilidade estrutural. Este estudo apresenta uma formulação transiente baseada no Método dos Elementos de Contorno (MEC) para a avaliação do tempo de início da corrosão. Os campos transientes avaliados pelo MEC são utilizados em uma modelagem probabilística, a qual possibilita a avaliação de valores probabilísticos para o tempo de início da corrosão. Portanto, a formulação representa adequadamente as incertezas deste problema, o qual é largamente sujeito aos efeitos das aleatoriedades. Três exemplos são apresentados. A robustez e a precisão da abordagem proposta sobre modelos analíticos clássicos é destacada.
\end{abstract}

Palavras-chave: ingresso de cloreto, método dos elementos de contorno, modelagem probabilística, transporte tipo difusão.

How to cite: G. P. Pellizzer and E. D. Leonel, "Probabilistic corrosion time initiation modelling in reinforced concrete structures using the BEM," Rev. IBRACON Estrut. Mater., vol. 13, no. 4, e13409, 2020, https://doi.org/10.1590/S1983-41952020000400009

\section{INTRODUCTION}

The reinforced concrete (RC) structures have been widely utilized worldwide. The success of this structural system, particularly in civil engineering applications, may be attributed to some of its characteristics such as the adequate mechanical strength, affordability, versatility, chemical and thermal protection of steel, durability in addition to the financial aspects. Nevertheless, pathological problems reduce the service life of such structures. Among these problems,

Corresponding author: Edson Denner Leonel. E-mail: edleonel@sc.usp.br

Financial support: This study was financed in part by the Coordenação de Aperfeiçoamento de Pessoal de Nível Superior - Brasil (CAPES) - Finance Code 001. Conflict of interest: Nothing to declare. 
sulphate expansion, alkali-aggregate reaction, leaching and reinforcements' corrosion are mentioned [1]-[3]. Moreover, it is worth highlighting that the reinforcements' corrosion have caused enormous economic loss worldwide. It is estimated that the costs with inspection, maintenance and repair caused by reinforcements' corrosion reach $4 \%$ of the Gross Domestic Product (GDP) in industrialized countries and exceeds US\$ 1.8 trillion worldwide [4], [5].

The reinforcements' corrosion occurs through chemical and/or electrochemical reactions. In RC structures, the reinforcements are protected against such reactions by the passivating layer. This thin layer surrounding the reinforcements is chemically stable because of the alkalinity of the aqueous solutions at the concrete pores. Nevertheless, the chemical effects of $\mathrm{Cl}^{-}$ions into the concrete pores disturb the chemical stability of this layer [6]-[8]. Particularly, the corrosion process triggers when the $\mathrm{Cl}^{-}$concentration at the passivating layer reaches the threshold content. In this case, the depassivation phenomenon occurs.

The classic approach for RC durability assessment divides the structural service life into two periods: initiation period and propagation period [9], [10]. The initiation period concerns the time span from the construction until the reinforcements' depassivation. This period is governed by diffusion-like transport mechanisms such as the $\mathrm{Cl}^{-}$into the concrete pores. On the other hand, the propagation period refers to the reinforcements' mass loss and the mechanical degradation properties along time. It is well-established that the propagation period is shorter than the initiation period [11], [12]. Because the corrosion products occupy larger volume than the initial configuration, internal stresses lead to the cracking and spalling, as observed in Figure 1. Then, the accurate prediction and modelling of the initiation period have major importance for structural engineering applications in order to avoid and to prevent complex and faster mechanical degradation phenomena.

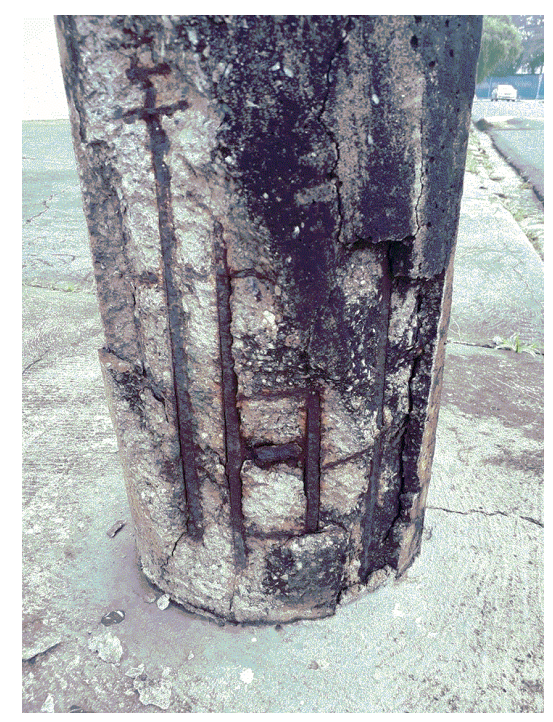

Figure 1 - Reinforcements' corrosion in a reinforced concrete column.

The $\mathrm{Cl}^{-}$ions ingress into the concrete pores involves dynamic and nonlinear processes, which include several transport mechanisms such as ionic diffusion, capillarity absorption, advection, chemical activity, permeation and dispersion [13]-[15]. In spite of the large complexity of this phenomenon, it is often modelled exclusively through the diffusion-like transport mechanism [16]-[18]. The pure diffusion assumptions are properly applied when saturated conditions are observed in concrete pores. It is worth mentioning that when tidal zones are accounted, the $\mathrm{Cl}^{-}$ingress has significant influence of capillarity absorption in addition to advection.

The chloride diffusion process is commonly modelled through analytical or empirical approaches available in the literature [19]-[21]. Among them, it is worth citing the Fick's approach [22]-[25]. The first Fick's law is applicable for steady-state processes. The second Fick' law, which represents the transient condition, is written as a function of time. The latter law of diffusion assumes the material as homogeneous, isotropic and inert. Moreover, the material properties during the diffusion phenomenon are assumed as equal along all directions and remain constant along time [26], [27]. In addition, the Fick's law solution is obtained from semi-infinite domains, in which the boundary conditions are assumed as constant along time and the flux occurs in one-directional form. It is worth 
stressing that, in spite of been largely utilized in the literature, the Fick's approach incorporates inherent strong simplifications, which make it non-robust and inaccurate for a large amount of applications.

To handle properly the $\mathrm{Cl}^{-}$diffusion into concrete pores, numerical methods have been successfully applied along the last years. Among them, it is worth citing the Finite Element Method (FEM), which was largely utilized for this purpose [28]-[32]. In addition, improved FEM approaches, such as the eXtended FEM (XFEM) has been also utilized for solving this problem [33], [34]. In the latter case, improved shape functions enable the accurate representation of the diffusion fields. In both cases, domain meshes are required, i.e. domain approximation, in spite of the boundary conditions are applied at the bodies boundaries. Moreover, both approaches require much finer discretisation in both the spatial and temporal domains, which results in large amount of unknowns and large computational time consuming.

Alternatively, the Boundary Element Method (BEM) handles accurately the diffusion modelling. In this numerical method, the governing differential equations are written into integral form at the body's boundary. Then, the BEM enables the mesh dimensionality reduction by one order. Moreover, the BEM does not require a domain mesh for solving the boundary value problem. Therefore, the internal diffusion fields are accurately determined since the boundary values are properly assessed [35]. This characteristic has major importance for assessing the corrosion time initiation because the $\mathrm{Cl}^{-}$concentration along time and along the material domain is accurately determined by the BEM. Thus, this characteristic makes the BEM accurate for solving the corrosion time initiation problem. In addition, the diffusion problem is solved by small algebraic system of equations (in comparison with domain methods) because the mesh is positioned solely at the boundary [35], [36]. In spite of the above-mentioned advantages, the BEM has been marginally utilized for handling the corrosion time initiation problem. Particularly [37], [38], utilized the diffusion BEM formulation for assessing the chloride distribution along the concrete cover. The propagation period is modelled through commercial BEM and FEM software by Warkus et al. [39], in which the BEM advantages are highlighted. Chen and Leung [40] studied the durability of RC structures subjected to reinforcements' corrosion using the BEM approach. Thus, the present research contributes with this scientific domain by utilizing the transient BEM approach for the solution of time-dependent chloride diffusion into the concrete pores.

In spite of the large efforts dedicated towards the development of robust and general approaches for diffusion modelling, most of the models available in the literature utilize deterministic approaches for this purpose [11]. Moreover, it is well-known that the diffusion phenomenon is subjected to large randomness. Among the observed randomness aspects, it is worth citing: chloride binding capacity [41], [42], time and space effects on the coefficient of diffusion [43], [44], external variation of chloride concentration along time [45], [46], chemical composition of concrete [47]-[49], concrete curing process [21], [50], [51], critical chloride content [52], among others. Therefore, this complex engineering problem is solely analysed properly in the context of accurate numerical formulations coupled to probabilistic approaches. Then, the present study contributes with this scientific domain by coupling an accurate approach for diffusion with a probabilistic framework.

It is worth mentioning that the concepts of probabilistic modelling and life cycle are not included explicitly in several RC design codes. However, these concepts have evolved considerably in the last years. Significant advances were achieved concerning the design, monitoring, maintenance and repair phases [53], [54]. Nevertheless, these studies do not account for robust numerical approaches for representing the diffusion problem, which highlight the importance of the model proposed in the present study.

In this context, the present study proposes a diffusion-probabilistic framework for the robust and accurate modelling of $\mathrm{Cl}^{-}$diffusion into concrete pores. The proposed model handles the corrosion time initiation taking into account the inherent problem randomness. The diffusion process is modelled by the BEM, in which transient conditions are accounted. Therefore, time dependent boundary conditions are properly represented by the BEM. Moreover, the BEM model is capable of simulating multi-directional domain flux caused by external $\mathrm{Cl}^{-}$. It is worth mentioning that these aspects make the proposed model superior to the empirical approaches utilized in the literature. High-order boundary elements are available for spatial integration. The temporal integration is performed by the constant approach. The randomness's are quantified by the Monte Carlo simulation method. This approach has been utilized because of the adequate computational performance of the BEM model. Moreover, because domain mesh (domain approximation) is not required by BEM, accurate values for $\mathrm{Cl}^{-}$concentration at the material domain are assessed.

The proposed approach is applied in the analysis of three applications. The first application handles the comparative analysis against the Fick's modelling, in which the robustness of the BEM is demonstrated. The limitations of the analytical approach are also emphasized. The second and third applications concern the analyses of complex RC cross-sections, in which complex boundary conditions are applied along time. In both cases, accurate responses are obtained. 


\section{THE BOUNDARY ELEMENT FORMULATION}

\subsection{Governing Equations and Boundary Integral Equation}

Classical potential problems are properly represented by the Poisson's equation. This equation enables the representation of thermal conductivity, torsion, conduction of fluids, among others, accounting for time independent conditions. The Poisson's equation is written as follows:

$\nabla^{2} u+b=0$

where $u$ is the potential and $b$ represents the domain term. When the domain term is nil, a particular case is obtained, which is named as Laplace.

Equation 1 is solved by enforcing boundary conditions as follows:

- Essential: $u=\bar{u}$ in $\Gamma_{1}$

- Natural: $q=\bar{q}=\frac{d u}{d \eta}$ in $\Gamma_{2}$

in which $\bar{u}$ indicates the prescribed potential value, $\bar{q}$ represents the prescribed flux value, $\Gamma_{1}$ and $\Gamma_{2}$ are the boundaries where potential or flux are prescribed, respectively. The flux is defined as $q=\frac{d u}{d \eta}$, which is the directional derivative of $u$ in relation to the outward normal vector $\eta$, as illustrated in Figure 2.

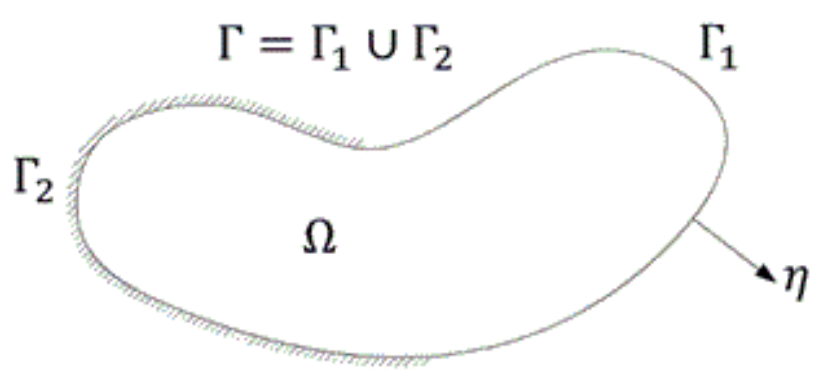

Figure 2 - Domain, boundaries and outward vector

Equation 1 represents properly the values of potential and flux for time independent conditions. Therefore, this approach is not accurate for representing the evolution of these diffusion fields during transient analyses. To incorporate time dependent boundary conditions or even for analysing the evolution of the diffusion fields along time, the transient approach must be accounted. The differential equation that governs the transient potential problem is the following:

$\nabla^{2} u-\frac{1}{\kappa} \frac{\partial u}{\partial t}=0$

where $\kappa$ is the domain-related parameter, such as thermal diffusivity or diffusion coefficient and $t$ is time. The last equation is solved by enforcing the boundary conditions, similarly as described for Equation 1. Then, the potential and flux values at the boundary must be prescribed at each time step. It is worth mentioning that the diffusion problems 
analysed in the present study apply Equation 2. In such case, the potential values represent the chloride concentration along time whereas the flux represents the chloride flux along the time.

The differential equation Equation 2 can be transformed into a boundary integral representation by utilizing either the Laplace transform, the finite differences technique or the fundamental time dependent solutions [35], [55]-[57]. The latter approach is utilized in the present study. The boundary integral representation for the transient problem is achieved by applying the Green's second identity at the Equation 2. Afterwards, the integration by parts is applied. Finally, the usual limit process, necessary to evaluate the integral equation at the boundary, is performed. The abovementioned procedures lead to the following integral representation, in which spatial and temporal integrations are required:

$$
c(\underline{\xi}) u\left(\underline{\xi}, t_{F}\right)=\kappa \int_{t_{0} \Gamma}^{t_{F}} \int q(\underline{x}, t) u^{*}\left(\underline{\xi}, \underline{x}, t_{F}, t\right) d \Gamma(\underline{x}) d t-\kappa \int_{t_{0} \Gamma}^{t_{F}} \int u(\underline{x}, t) q^{*}\left(\underline{\xi}, \underline{x}, t_{F}, t\right) d \Gamma(\underline{x}) d t
$$

where $\underline{\xi}$ refers to the source points, $\underline{x}$ represents the field points, $t_{0}$ indicates the initial time, $t_{F}$ is the observation time, $u^{*}$ and $q^{*}$ are the fundamental time-dependent solutions for potential and flux, respectively, and $c$ is the free term. The parameter $c$ is equal to 1 for source points positioned at the domain. Otherwise, this parameter is equal to 0.5 for source points positioned at smooth boundary geometries. In two-dimensional case, the fundamental solutions are the following [35], [58]:

$$
u^{*}\left(\underline{\xi}, \underline{x}, t_{F}, t\right)=\frac{1}{4 \pi \kappa \tau} \exp \left(-\frac{r^{2}}{4 \kappa \tau}\right)
$$

$q^{*}\left(\underline{\xi}, \underline{x}, t_{F}, t\right)=\frac{r \frac{\partial r}{\partial \eta}}{8 \pi \kappa^{2} \tau^{2}} \exp \left(-\frac{r^{2}}{4 \kappa \tau}\right)$

in which $\tau=t_{F}-t, r$ indicates the distance between the source $\underline{\xi}$ and the field $\underline{x}$ points and $\frac{\partial r}{\partial \eta}=r_{, k} \eta_{k}$.

\subsection{Algebraic Equations}

The potential and flux values at the boundary for a given time step are evaluated by Equation 3. Thus, spatial and temporal integrations must be performed to solve this equation. The spatial integration is performed by dividing the boundary geometry into boundary elements over which geometry and diffusion fields are approximated by shape functions. In the present study, polynomial functions are utilized for this purpose. The temporal integration is performed accounting for constant approximation. In the latter case, the time dependent kernels required by the BEM are integrated analytically.

Therefore, the discretisation of the body's boundaries $\Gamma$ into Ne boundary elements, the discretisation of the time interval $t_{F}-t_{0}$ into $N t$ time steps and inverting the integration order lead to the following:

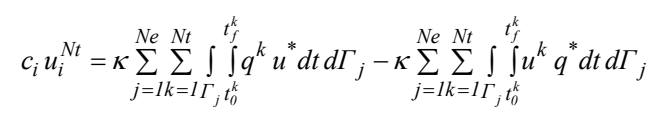

in which $u_{i}^{N t}$ indicates the potential value at the time $t^{N t}$ for a given source point $i$. The last equation is rewritten bearing in mind that functions $u^{*}$ and $q^{*}$ are constantly integrated along time during each time step. In addition, it is assumed that source points are positioned at smooth boundaries. Thus: 
$0.5 u_{i}^{N t}=\kappa \sum_{j=I \Gamma_{j}}^{N e} \sum_{k=1}^{N t} q^{k_{t}^{k_{t}^{k}}} \int_{t_{0}^{k}}^{t^{k}} d t d \Gamma_{j}-\kappa \sum_{j=I \Gamma_{j}}^{N e} \sum_{k=1}^{N t} u^{k_{t}^{t_{f}^{k}}} \int_{t_{0}^{k}}^{*} d t d \Gamma_{j}$

Because the temporal integration is constantly performed, the last equation is rewritten as follows [35]:

$0.5 u_{i}^{N t}=\kappa \sum_{k=1}^{N t}\left(\sum_{j=1}^{N e} q_{j}^{k} \int_{\Gamma_{j}} U_{k}^{*} d \Gamma_{j}-\sum_{j=l}^{N e} u_{j}^{k} \int_{\Gamma_{j}} Q_{k}^{*} d \Gamma_{j}\right)$

in which the analytical evaluation of the fundamental solutions along time lead to the following [35]:

$$
\begin{aligned}
& U_{k}^{*}=\int_{t_{0}^{k}}^{t_{f}^{k}} u^{*} d t=\frac{1}{4 \pi \kappa}\left\{E_{I}\left[\frac{r^{2}}{4 \kappa\left(t_{F}-t_{0}^{k}\right)}\right]-E_{I}\left[\frac{r^{2}}{4 \kappa\left(t_{F}-t_{f}^{k}\right)}\right]\right\} \\
& Q_{k}^{*}=\int_{t_{f}^{k}}^{t_{f}^{k}} q^{*} d t=\frac{1}{2 \pi r \kappa} \frac{\partial r}{\partial \eta}\left\{\exp \left[-\frac{r^{2}}{4 \kappa\left(t_{F}-t_{0}^{k}\right)}\right]-\exp \left[-\frac{r^{2}}{4 \kappa\left(t_{F}-t_{f}^{k}\right)}\right]\right\}
\end{aligned}
$$

where $E_{1}$ represents the exponential-integral function.

As usual in BEM, Equation 8 is rewritten in terms of the influence matrices $H$ and $G$. Thus:

$0.5 u_{i}^{N t}=\sum_{k=1}^{N t}\left(\sum_{j=1}^{N e} G_{i j}^{k} q_{j}^{k}-\sum_{j=1}^{N e} \widehat{H_{i j}^{k}} u_{j}^{k}\right)$

where $H$ and $G$ are the influence matrices containing the integral kernels as follows:

$G_{i j}^{k}=\int_{\Gamma_{j}} U_{k}^{*} d \Gamma_{j}$

$\widehat{H_{i j}^{k}}=\int_{\Gamma_{j}} Q_{k}^{*} d \Gamma_{j}$

$H_{i j}^{k}=\left\{\begin{aligned} \widehat{H_{i j}^{k}}+0.5 & \text { if } k=1 \text { and } i=j \\ \widehat{H_{i j}^{k}} & \text { otherwise }\end{aligned}\right.$

Thus, the classical BEM system of equations is obtained as follows:

$$
H U=G Q
$$

where $H$ and $G$ are $N x N$ matrices containing the influence coefficients obtained from Equation 13 and Equation 14. $N$ indicates the amount of collocation points into the boundary mesh.

The final system of equations is obtained by imposing the boundary conditions of the analysed problem into Equation 15. Then, the unknown values at the boundary are moved to the left side of the equation whereas the known 
values are moved to the right side. This process is accompanied by the columns exchange between $H$ and $G$ matrices, which leads to the following:

$A X=F$

where $A$ is a matrix composed of the coefficients from $H$ and $G$ associated with the unknown values, $X$ is a vector containing the unknown values at the boundary and $F$ is a vector obtained from the multiplication of the known values and their respective coefficients. The solution of Equation 16 provides the unknown values at the body's boundary.

Because transient analysis is performed, the diffusion fields at the present time are functions of the time history field values. Therefore, a time marching process is required. The constant approach is applied in the present model. Thus, the marching process is as follows [35]:

$H_{t_{f}} U_{t_{f}}=G_{t_{f}} Q_{t_{f}}+S_{f}$

in which $S_{f}$ is evaluated as follows:

$S_{f}=-\sum_{j=1}^{f-l} H_{j} U_{j}+\sum_{j=1}^{f-l} G_{j} Q_{j}$

Then, the $S_{f}$ vector is added to the $F$ vector contained in Equation 16 to account for the time history effects.

The integration of the above-presented kernels is performed numerically. Nevertheless, the singular nature of the fundamental solutions requires special attention. The standard Gauss-Legendre quadrature is utilized when the integrated boundary element does not contain the source point. In this case, the kernels are regular. The kernels are improper for singular elements, i.e., when the integrated boundary element contains the source point. For such case, the singularity-subtraction method is utilized. By this approach, an auxiliary kernel with the same singularity order is subtracted and added to the original singular kernel. The procedure leads to a regular integral and to a new singular kernel, in which the latter has analytical solution. Then, the regular part is evaluated by the standard Gauss-Legendre quadrature whereas the analytical solution is achieved by the Cauchy principal value. This procedure enables the diffusion analyses accounting for high-order boundary elements. In addition, curved geometries are properly analysed. The analytical solution provided by the Cauchy principal value is demonstrated in Appendix A.

It is worth mentioning that Equation 6 enables the assessment of internal potential fields, in addition to the boundary values as previously mentioned. In such case, the free term $c$ equals 1 because the source point is positioned in the domain. Because the kernels are regular for such case, all integrals are evaluated using the standard Gauss-Legendre quadrature.

\section{UNCERTAINTY QUANTIFICATION MODELLING}

The probabilistic approaches enable the assessment of the probability of failure, $P_{f}$, accounting for specific failure scenarios, which are formally named as limit states. In such analysis type, the set of random variables $\boldsymbol{X}=\left[x_{1}, x_{2}, \ldots, x_{n}\right]^{T}$ must be initially identified. Then, individual probability distributions are attributed to such variables for modelling the individual randomness.

Afterwards, the failure modes must be defined/identified. The limit state function, $G(\boldsymbol{X})$, for each failure mode is defined, which separates the random space into two parts: the safe domain, $G(\boldsymbol{X})>0$, and the failure domain, $G(\boldsymbol{X})<0$. The $G(\boldsymbol{X})=0$ indicates the interface between the domains, which is named as the limit state itself. Therefore, the probability of failure indicates the probability of the structural system does not accomplish one or more than one design requirements.

It is worth mentioning that explicit expressions for limit states are not usually available in complex engineering problems. Particularly, when numerical models represent the phenomenon behaviour, solely the limit state values are known at an informed amount of points. The probability of failure is assessed by the integration of the joint density function along the failure domain [59]. Therefore, the probability of failure is evaluated as follows: 
$p_{f}=P[G(\boldsymbol{X})<0]=\int \ldots \int_{G(\boldsymbol{X})<0} f_{\boldsymbol{X}}(\boldsymbol{x}) d \boldsymbol{x}$

in which: $f_{\boldsymbol{X}}(\boldsymbol{x})$ is the joint density function of the random variables $\boldsymbol{X}$.

The explicit assessment of Equation 19 for complex engineering problems is impossible because the limit state function and consequently the failure and safe domains descriptions are implicit. Therefore, for such particular case, this integral is evaluated by simulation techniques. The most important simulation technique is the Monte Carlo simulation method (MCSM). In a brief overview, the MCSM assesses the probability of failure from a sampling of random variables, which simulates the limit state function. Then, the structural failure is observed when the sampling points leads to the failure domain. Otherwise, safe condition is observed. The probability of failure is assessed by the simulation technique through the ratio between the sampling points at the failure domain and the total amount of simulations. Thus:

$$
p_{f}=\int_{\Omega} I[\boldsymbol{x}] f_{\boldsymbol{X}}(\boldsymbol{x}) d \boldsymbol{x}=\frac{1}{n_{t}} \sum_{j=1}^{n_{t}} I\left[\boldsymbol{x}_{j}\right]=\frac{n_{f}}{n_{t}}
$$

in which $n_{t}$ is the sampling range and $n_{f}$ the amount of observed failures. $I[x]$ is 1 for failure condition and nil for safe condition.

This simulation technique requires wide range of sampling for describing properly the failure and safe domains and, consequently, for achieving accurate results. Consequently, non-efficient numerical models lead to the unreliable coupling approaches. Nevertheless, the MCSM is utilized in the present study because the BEM formulation is efficient in terms of computational cost. It is worth citing that convergence analyses are recommended to verify the accuracy of the results obtained throughout the simulations. Convergence rate and its stability are directly influenced by the amount of random simulations.

It is worth mentioning that gradient-based techniques, such as First Order Reliability Method (FORM) or Second Order Reliability Method (SORM) could be applied for solving Equation 19. However, these methods require derivatives of the limit state functions, which, in such case, are assessed numerically. In addition to the numerical errors associated to the derivatives evaluation, the gradient-based techniques may lead to the local minima solutions. Therefore, in spite of the computational cost associated to the MCSM, it is certainly more robust than the gradientbased approaches.

In the present study, the limit state function depends on the time as follows:

$G(\boldsymbol{X})=R(\boldsymbol{X})-S(\boldsymbol{X}, t)$

in which $R$ indicates the chloride threshold content value, which is a function of the concrete composition. Then, $R$ indicates the material resistance against depassivation. $S$ represents the chloride concentration at the analysed point. In the present study, the BEM model determines the chloride concentration value along time for the analysed point. Therefore, the $S$ is assessed by the BEM whereas $R$ is informed during the analysis. Then, the $S$ value is a function of the material properties, structural geometry and chloride concentration at the exterior boundary. It is worth stressing that $S$ is accurately evaluated by the BEM because of the method characteristics mentioned in section 2.

\section{SUMMARY OF THE PROPOSED NUMERICAL MODEL}

The diffusion-probabilistic model proposed in the present study runs as summarized in Figure 3. Then, the MCSM is initialized, in which a sample for the random variables is generated. It is worth stressing that these samples are generated as a function of the statistical distribution type, mean and coefficient of variation assigned for each random variable. These information enable the input for the BEM diffusion model.

The potential, i.e., the chloride concentration, at the material domain along time is determined by the BEM accounting for the sample values. As illustrated in Equation 21, failure occurs at a given time step $k$ when the chloride concentration at the analysed point is higher than the chloride threshold content. Otherwise, safe condition is observed. 


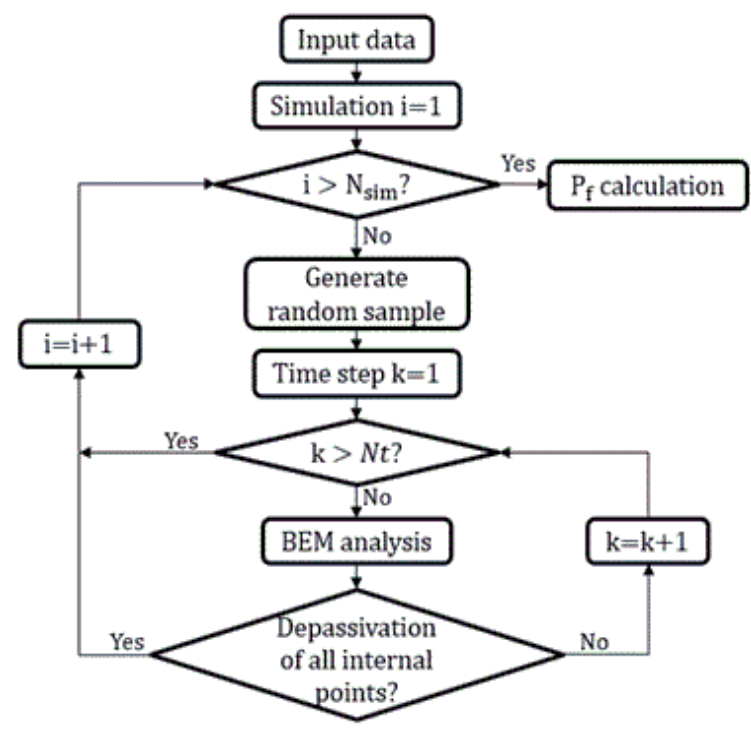

Figure 3 - Flowchart of the proposed numerical approach

\section{APPLICATIONS}

The diffusion-probabilistic framework proposed in the present study is utilized in the analysis of three applications. The first application concerns the deterministic comparison among the responses of the BEM and the Fick's law. This application illustrates the limitations of the Fick' law in general diffusion problems. The probabilistic modelling is included in the second and third applications. The second application handles the probabilistic diffusion modelling accounting for a rectangular cross-section. Similar analysis is performed in the third application, in which a T-shape cross-section is accounted. The statistical distribution assigned for each random variable is based on the literature references, especially [20], [60].

\subsection{Application 1}

The chloride diffusion transport in a rectangular $180 \times 90 \mathrm{~mm}$ domain composed of concrete is analysed in the present application. A reinforcement of $10 \mathrm{~mm}$ diameter is assumed as a part of the specimen, as illustrated in Figure 4. Thus, the chloride concentration along time at the reinforcement position is evaluated in this application.

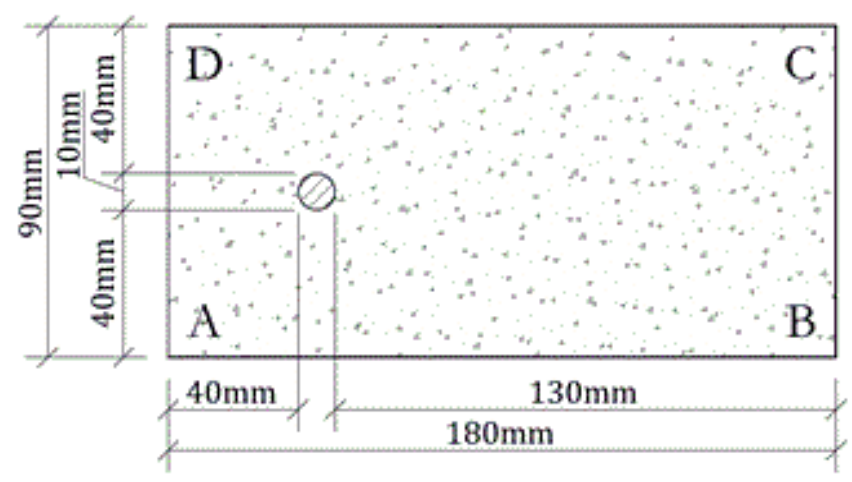

Figure 4 - Application 1. Specimen geometry dimensions

The diffusion responses achieved by the BEM are compared against the Fick's results. The chloride concentration by the Fick's approach is evaluated along time as follows [9]: 


$$
C(x, t)=C_{s} \operatorname{erfc}\left[\frac{x}{2 \sqrt{\kappa_{0} t}}\right]
$$

in which $C_{s}$ indicates the chloride concentration at the body's surface, $C(x, t)$ is the chloride concentration at the desired point along time, $t$ represents the time, $x$ is the distance of the analysed point until the structural surface, $\kappa_{0}$ is the coefficient of diffusion and erfc is the complementary error function.

The coefficient of diffusion can be calculated by following the procedures proposed by [61]. Then:

$$
\kappa_{0}=10^{-10+4.66 \mathrm{w} / \mathrm{c}}
$$

where $w / c$ is the water/cement ratio and $\kappa_{0}$ is the coefficient of diffusion in square centimetres per second. The water/cement ratio is assumed as 0.5 in the present analysis. Therefore, the coefficient of diffusion is equal to $2.137910^{-8} \mathrm{~cm}^{2} / \mathrm{s}=67.4228 \mathrm{~mm}^{2} /$ year, which is assumed as constant along time.

In the present application, the rectangular domain illustrated in Figure 4 is analysed accounting for four different boundary conditions, which compose the four cases shown in Figure 5.

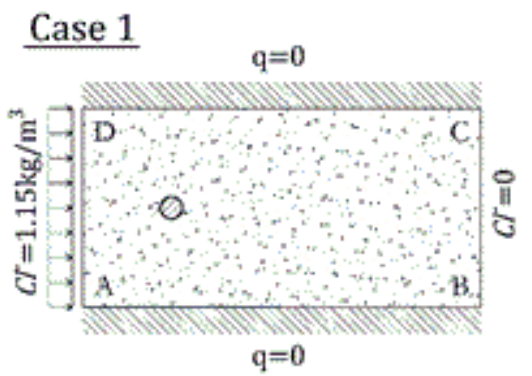

Case 3

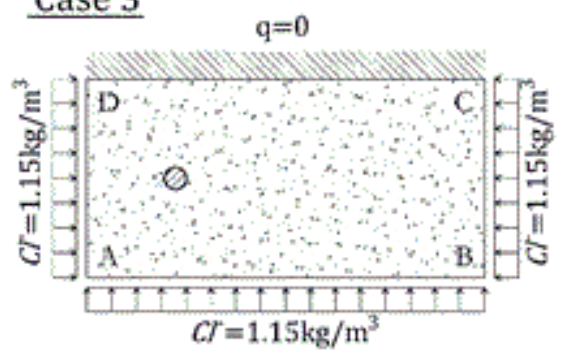

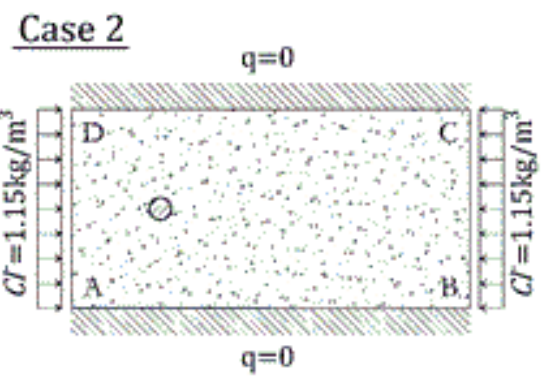
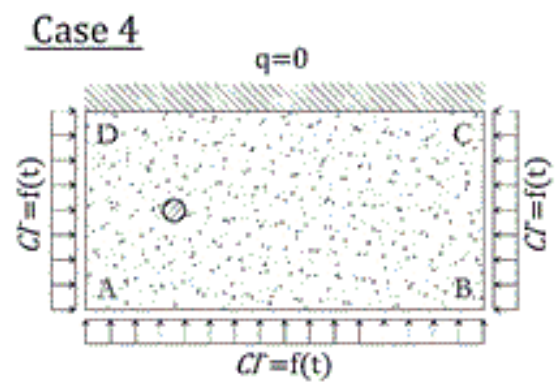

Figure 5 - Boundary conditions

The case 1 represents the pure one-directional flux, in which the chloride flux goes from the left to the right faces. The case 2 handles the mixed one-dimensional flux. In this case, the chloride flux occurs simultaneously from the left to the right faces and from the right to the left faces. The two-directional chloride flux is observed in case 3. It is worth citing that the boundary conditions illustrated for cases 1,2 and 3 are assumed as constant along time. Then, the case 4 is added to account for time dependent boundary conditions. In the latter case, the two-directional flux is simulated, in which the chloride concentration along time varies following the systematic behaviour illustrated in Figure 6. 


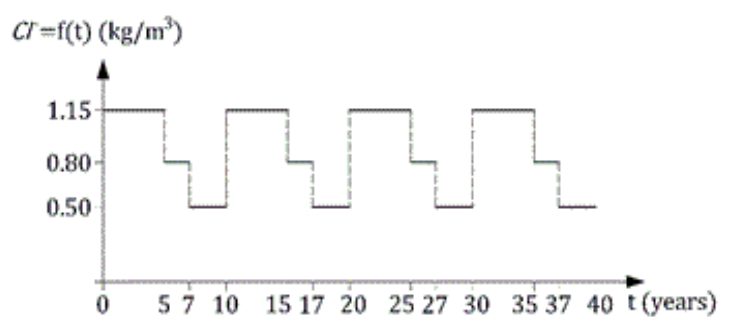

Figure 6 - Time dependent boundary conditions for case 4

It is worth emphasizing that the analytical approach incorporates inherent simplifications, as previously mentioned. Because of them, solely the boundary conditions of case 1 comply with the model requirements. Thus, this application illustrates the limitations of Fick's model and the necessity of robust approaches for solving properly this problem.

The mesh utilized by the BEM simulations is composed of 54 linear isoparametric discontinuous boundary elements, which lead to the 108 collocation points. In addition, 40 time steps were utilized for the temporal integration. Moreover, it is assumed that $u=q=0$ in $t=0$. The space and time discretisations have been determined accounting for standard convergence procedure. Then, further refined discretisation do not introduce significant changes into the mechanical modelling.

Internal points were added to determine the chloride concentration behaviour along time into the concrete specimen. Such points are spaced from $2 \mathrm{~mm}$ each other. Moreover, they were positioned at a virtual line connecting the midpoints of the boundaries $\mathrm{AD}$ and $\mathrm{BC}$. Therefore, the internal points intercept the reinforcement's position, as illustrated in Figure 4. The chloride concentration profiles determined by the BEM and via Fick's approach are illustrated in Figure 7. In this figure, the four different boundary conditions are illustrated.
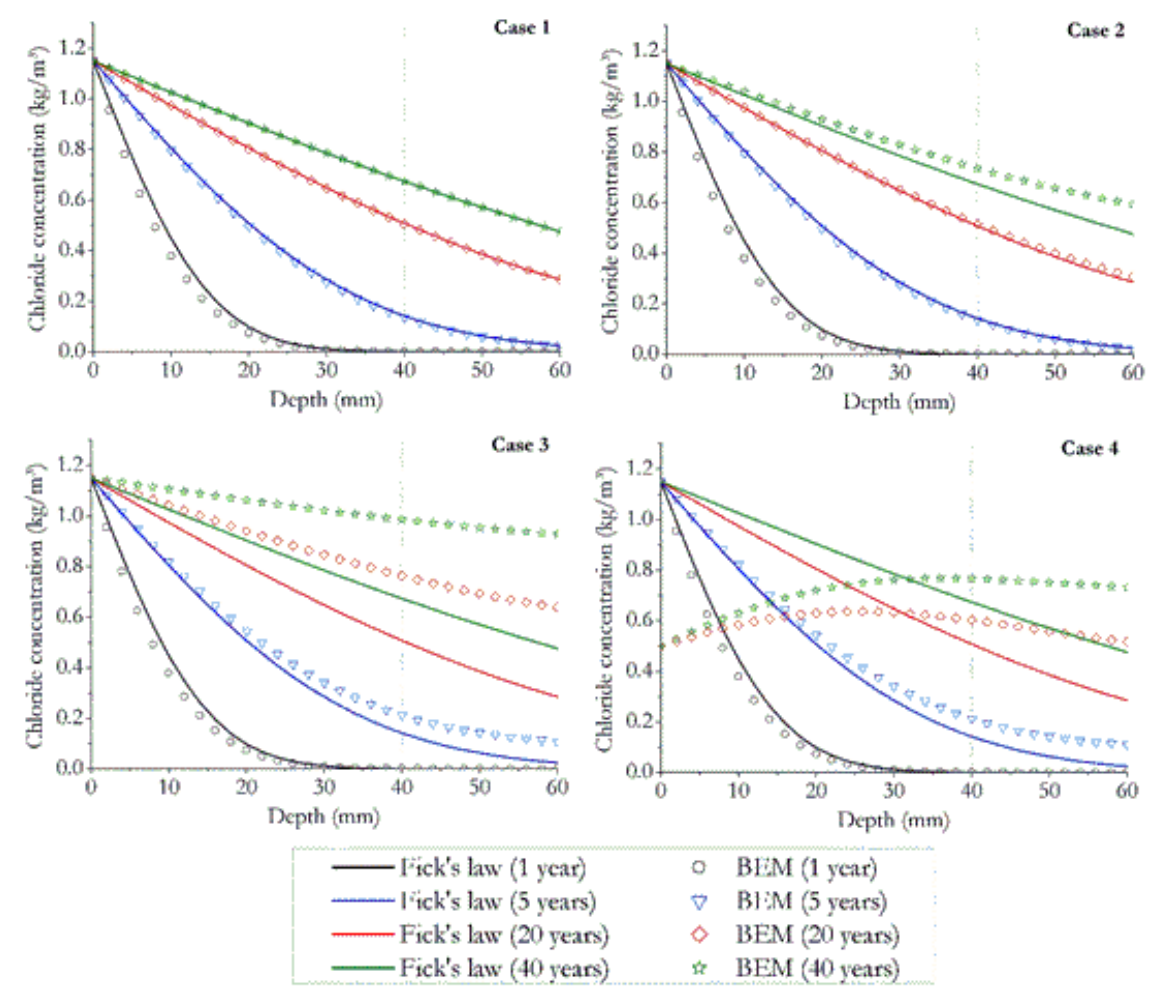

Figure 7 - Chloride profiles evolution along time for the four different boundary conditions 
Moreover, the evolution of the chloride concentration along time for the fixed reinforcement position, i.e. depth of $40 \mathrm{~mm}$, is illustrated in Figure 8.
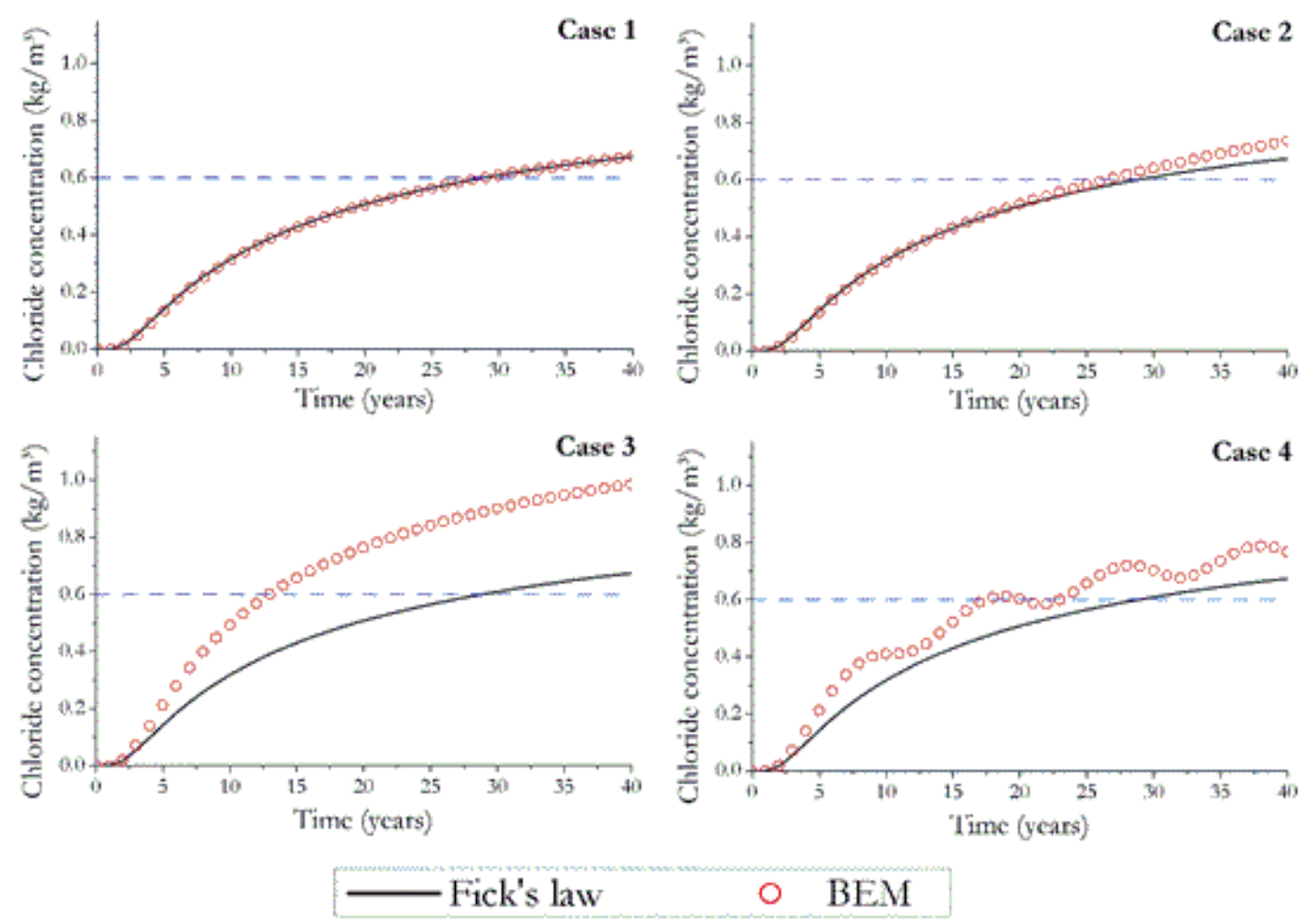

Figure 8 - Chloride concentration evolution along time for the fixed depth

Excellent agreement is observed among the numerical and analytical responses for case 1. This behaviour was expected because the Fick's hypotheses are well satisfied in the case. The responses differences for the years 5, 20 and 40 are $5.31 \%, 0.32 \%$ and $0.07 \%$, respectively. Moreover, assuming the threshold chloride content as $0.6 \mathrm{~kg} / \mathrm{m}^{3}$, for instance, both approaches lead to the same time for corrosion initiation, 29 years.

The case 2 presents similar behaviour when early ages are analysed. Then, good agreement is observed until 5 years. Nevertheless, important differences occur after 20 years, in spite of essentially one-dimensional diffusion transport is simulated. These differences appear due to the bidirectional chloride diffusion simulated in this case, which is not properly represented by the analytical approach. It is worth emphasizing that the influence of the bidirectional chloride diffusion is evident in case 3, in which essentially two-dimensional chloride diffusion is accounted. In the latter case, large differences are observed even in early ages. Moreover, the chloride concentration evolves faster along time, in this case, in comparison with one-directional cases. The corrosion time initiation is 26 years and 13 years for cases 2 and 3, respectively. Then, in comparison with case 1 , reductions of $10 \%$ and $55 \%$ are observed.

Finally, large behaviour differences among numerical and analytical responses are observed in case 4 . In this case, the chloride concentration at the specimen surface is a function of time. As expected, the numerical responses are capable to represent the time dependent behaviour. Nevertheless, such behaviour is not represented properly by the analytical approach. Actually, Fick's solution assumes time independent boundary conditions, which is not observed in practical engineering problems. The time for corrosion initiation determined by the BEM is 18 years, which is $38 \%$ shorter than in case 1 .

The present application illustrates some limitations of the Fick's law in simulating the chloride diffusion transport mechanism. Particularly, the limitations associated to the time dependent boundary conditions and multi-directional fluxes must be emphasized. In such cases, the hypotheses of Fick's approach are violated and this analytical approach does not represent properly the physical phenomenon. It is worth stressing that the 
cases 2, 3 and 4 concern practical diffusion problems, in which multi-directional fluxes are observed and time dependent chloride concentration at the surface occurs. In such cases, major differences of chloride concentration behaviour along time are observed. Thus, based on the present results, one emphasizes that Fick's law must be criteriously utilized. Moreover, its limitations must be accounted for the proper diffusion modelling.

\subsection{Application 2}

In this application, the diffusion-probabilistic modelling of the specimen illustrated in Figure 4 is presented. Thus, the geometry and boundary conditions discussed in the previous application are accounted. However, the randomness on problem variables is included and the uncertainties are quantified taking into account the corrosion time initiation. The limit state function utilized in the present analysis is as follows:

$G=t_{c}(X)-t_{S L}$

in which $t_{c}$ indicates the corrosion time initiation, which is a function of the random variables, X. $t_{S L}$ is the expected structural life time. Thus, positive values in Equation 24 indicate safe condition.

In this application, $t_{c}$ is calculated either by the BEM model or the Fick's approach. Moreover, the probability of failure is assessed by the MCSM. In this application, one verifies if the large differences behaviour observed in the last application lead to the similar differences behaviour on the values of probabilities of failure.

In this analysis, three random variables are considered. The statistical distributions assigned for each random variable as well as its statistical properties are described in Table 1. It is worth mentioning that the mean values for the chloride concentration at the surface for case 4 are presented in the previous application, Figure 6.

Table 1 - Statistical data for application 2

\begin{tabular}{lccc}
\hline \multicolumn{1}{c}{ Parameter } & Distribution type & Mean & C.O.V. \\
\hline Chloride threshold content $C_{\text {lim }}$ & Uniform & $0.60 \mathrm{~kg} / \mathrm{m}^{3}$ & 0.1443 \\
\hline Coefficient of Diffusion $\kappa_{0}$ & Lognormal & $67.7228 \mathrm{~mm}^{2} /$ year & 0.50 \\
\hline Chloride concentration at the Surface $C_{S}$ & Lognormal & $\begin{array}{c}1.15 \mathrm{~kg} / \mathrm{m}^{3} \text { (moderate } \\
\text { aggressiveness) }\end{array}$ & 0.50 \\
\hline
\end{tabular}

The BEM simulations required a mesh composed of 54 linear isoparametric discontinuous boundary elements, which lead to the 108 collocation points. In addition, 40 time steps were utilized for the temporal integration. Moreover, it is assumed that $u=q=0$ in $t=0$. The space and time discretisation have been determined accounting for standard convergence procedure. Then, further refined discretisation do not introduce significant changes into the mechanical modelling. The probability of failure was assessed at the internal points positioned following the pattern mentioned in the previous application. At each of these internal points, 10,000 Monte Carlo simulations were performed. It is worth mentioning that the range sample utilized in this application was sufficient for achieving the convergence during the probabilistic modelling.

The evolutions of the probability of failure along time for different depth values are illustrated in Figure 9. In this figure, the four different boundary conditions presented in the previous application are utilized. In addition, the evolution of the probability of failure along time for fixed depth values is presented in Figure 10. 

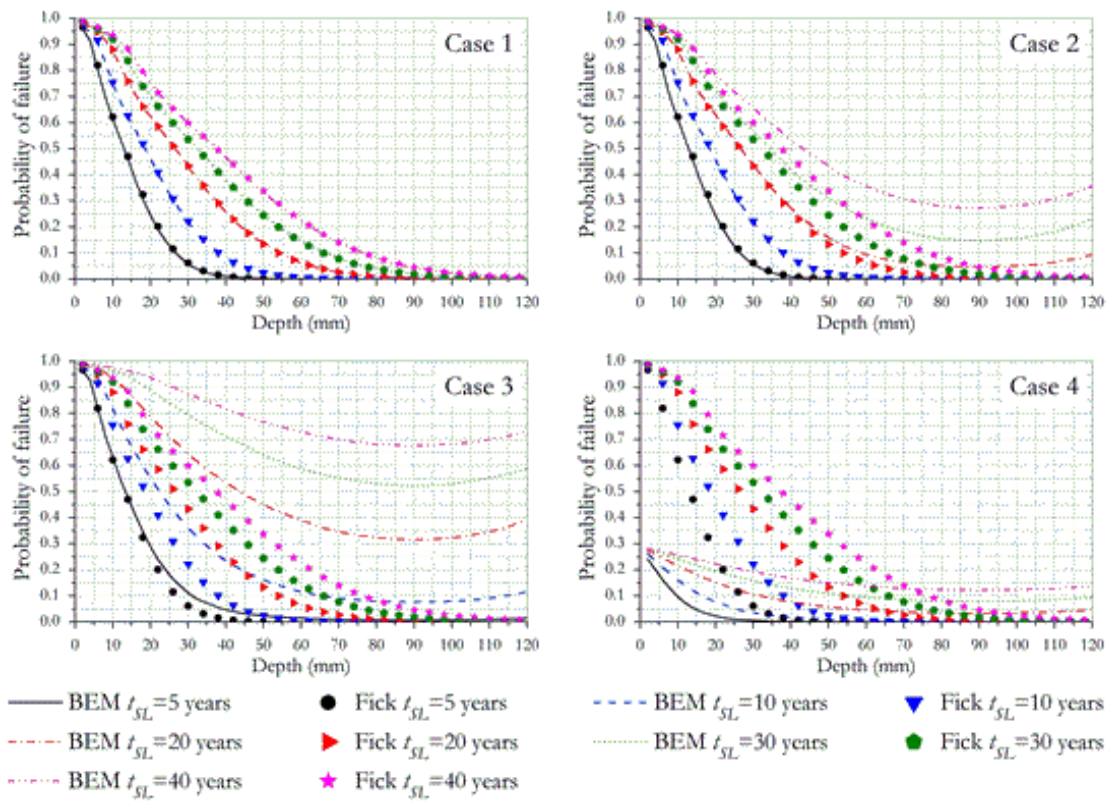

BEM $t_{S L}=30$ years Fick $t_{S L}=30$ years

Figure 9 - Evolution of the probability of failure along time.
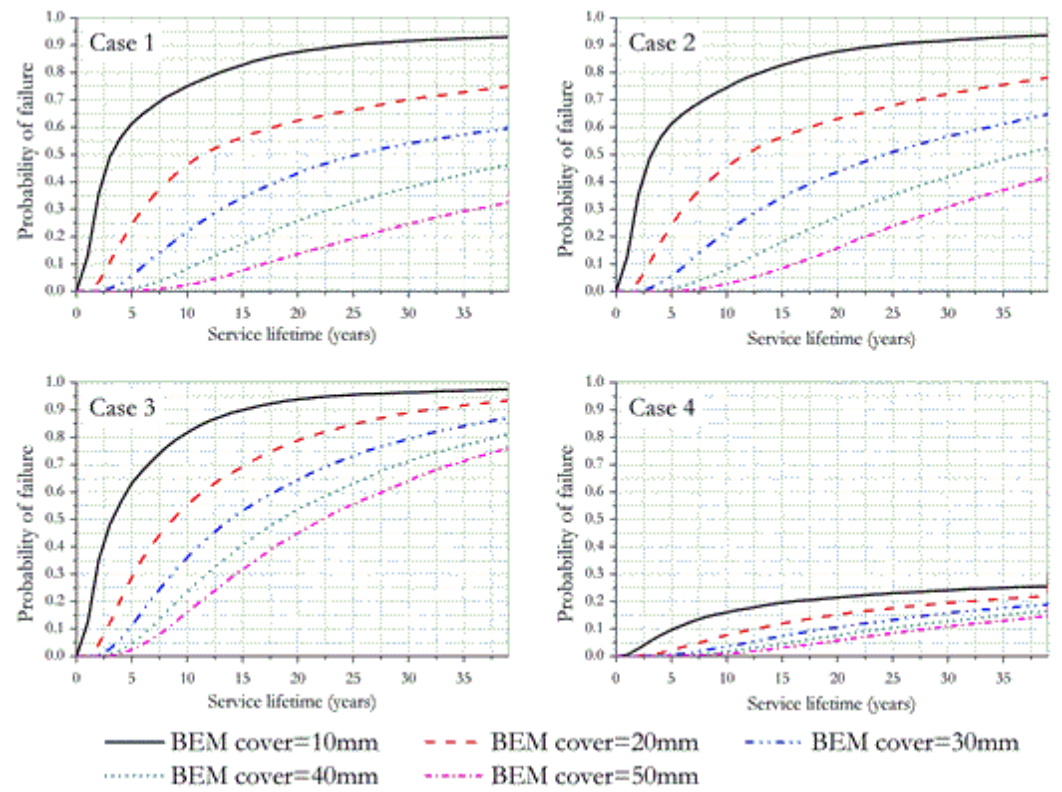

Figure 10 - Evolution of the probability of failure along time

Excellent agreement is observed among the probabilistic responses achieved by the BEM and the Fick's approach for case 1. This behaviour was expected because the chloride flux is essentially one-directional in this case. Nevertheless, major differences are observed for the other cases. Therefore, the probability of failure is largely dependent of the multi-directional flux condition in addition to the time dependent boundary conditions. This observation illustrates the weakness of the Fick's approach in simulating complex chloride ingress cases. Moreover, it demonstrates that numerical approaches are necessary to simulate properly this complex engineering problem.

It is worth mentioning that, in all cases, the probability of failure grows faster at small depths, as expected. The chloride concentration grows faster at those positions because of the near presence of chlorides at the surface. Therefore, fair cover depth values must be prescribed in structural design to assure adequate structural durability. 


\subsection{Application 3}

This application handles the diffusion-probabilistic modelling in the cross-section illustrated in Figure 11. This problem concerns a typical reinforced concrete beam connected to a concrete slab, which is largely utilized in bridge decks systems. The beam has rectangular cross-section of $20 \times 50 \mathrm{~cm}$ whereas the slab has $15 \mathrm{~cm}$ thickness. The resulting T-cross-section shape is subjected to chloride ingress along six of its boundaries. The upper boundary is subjected to external chloride concentration $C s_{1}$ and the lower boundaries are exposed to external chloride concentration $C s_{2}$. The cross-section dimensions and the boundary conditions are illustrated in Figure 11.



Figure 11 - Geometry and boundary conditions

The probabilistic modelling aims the determination of isoprobability of failure maps, which describe the evolution of the probability of failure along time for points that compose the cross-section domain. Thus, the limit state function considered in the present analysis is the illustrated in Equation 24. Such maps enable the accurate choice of the cover thickness by the analyst based on a given probability of failure target.

The diffusion analysis along time is performed by the BEM. The mesh utilized by the numerical model is composed of 74 quadratic isoparametric discontinuous boundary elements, which lead to the 222 collocation points. In addition, 33 time steps were utilized for the temporal integration, which cover the time span from 0 until 99 years. Moreover, it is assumed that $u=q=0$ in $t=0$. The space and time discretisation have been determined accounting for standard convergence procedure. Then, further refined discretisation does not introduce significant changes into the mechanical modelling.

The probabilistic modelling is performed accounting for the random variables described in Table 2. It is worth mentioning that three different environment aggressiveness were considered in the present analysis.

Table 2 - Statistical data for application 3

\begin{tabular}{|c|c|c|c|c|}
\hline $\begin{array}{c}\text { Environment } \\
\text { aggressiveness level }\end{array}$ & Parameter & $\begin{array}{l}\text { Distribution } \\
\text { type }\end{array}$ & Mean & C.O.V. \\
\hline All & Chloride threshold content $C_{\text {lim }}$ & Uniform & $0.90 \mathrm{~kg} / \mathrm{m}^{3}$ & 0.19 \\
\hline All & Coefficient of Diffusion $\kappa_{0}$ & Lognormal & $0.2305720 \mathrm{~cm}^{2} /$ year & 0.50 \\
\hline \multirow{2}{*}{ Moderate/Normal } & $\mathrm{Cl}^{-}$concentration at the surface $C s_{1}$ & \multirow{2}{*}{ Lognormal } & $1.15 \mathrm{~kg} / \mathrm{m}^{3}$ & \multirow{2}{*}{0.50} \\
\hline & $\mathrm{Cl}^{-}$concentration at the surface $\mathrm{Cs}_{2}$ & & $0.92 \mathrm{~kg} / \mathrm{m}^{3}$ & \\
\hline \multirow{2}{*}{ High } & $\mathrm{Cl}^{-}$concentration at the surface $C s_{1}$ & \multirow{2}{*}{ Lognormal } & $2.95 \mathrm{~kg} / \mathrm{m}^{3}$ & \multirow{2}{*}{0.75} \\
\hline & $\mathrm{Cl}^{-}$concentration at the surface $C s_{2}$ & & $2.36 \mathrm{~kg} / \mathrm{m}^{3}$ & \\
\hline \multirow{2}{*}{ Extreme } & $\mathrm{Cl}^{-}$concentration at the surface $C s_{1}$ & \multirow{2}{*}{ Lognormal } & $7.35 \mathrm{~kg} / \mathrm{m}^{3}$ & \multirow{2}{*}{0.75} \\
\hline & $\mathrm{Cl}^{-}$concentration at the surface $C s_{2}$ & & $5.88 \mathrm{~kg} / \mathrm{m}^{3}$ & \\
\hline
\end{tabular}

The probability of failure was assessed by the MCSM. For each environment aggressiveness, 10,000 simulations were performed to assess the probability of failure. It is worth mentioning that the sample range was sufficient for achieving the probabilistic convergence, as illustrated in Appendix B. Such method simulated the limit state function into 386 internal points, 
which were distributed into an uniform grid at the cross-section domain. Therefore, the probability of failure is assessed for each internal point. Based on these responses, a map of isoprobability of failure is obtained.

The isoprobability of failure maps for normal, high and extreme environment aggressiveness are shown in Figure 12, Figure 13 and Figure 14, respectively. The expected structural life time of 25 years and 50 years are considered.
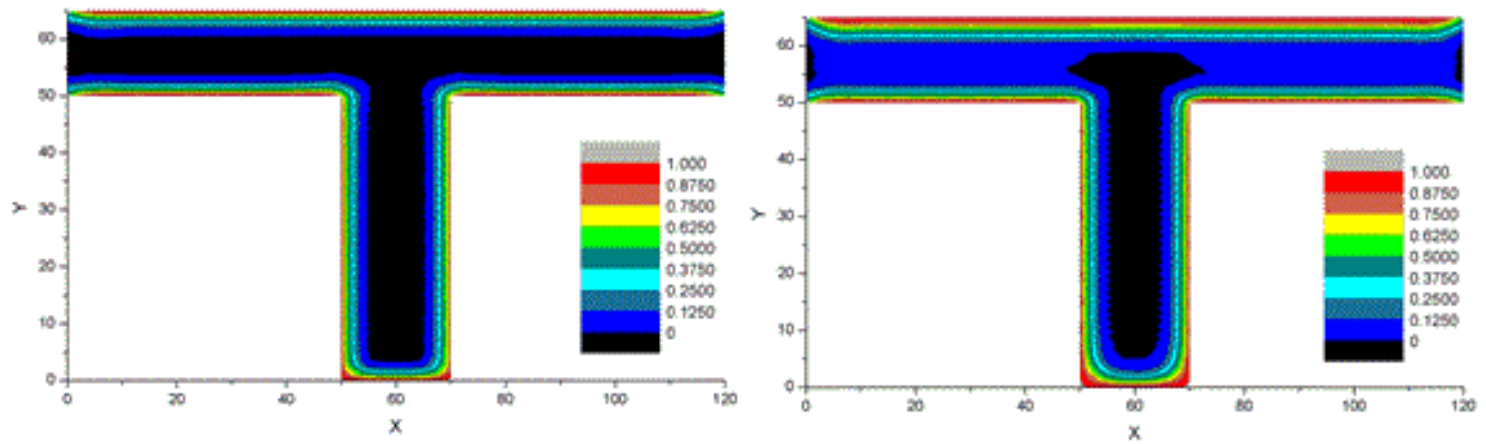

Figure 12 - Isoprobability maps for 25 years and 50 years. Normal environment aggressiveness.
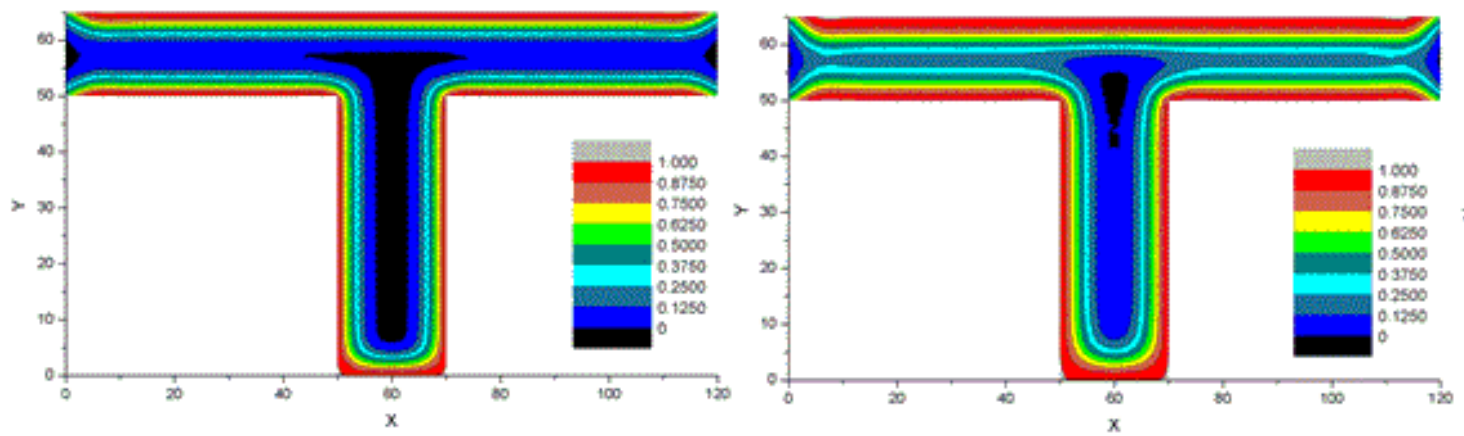

Figure 13 - Isoprobability maps for 25 years and 50 years. High environment aggressiveness.
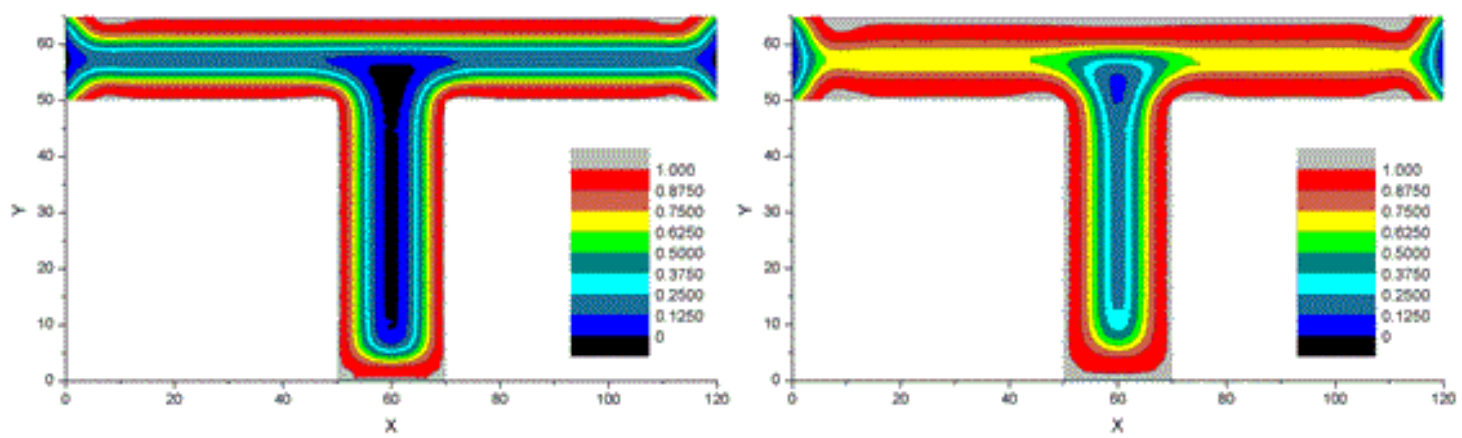

Figure 14 - Isoprobability maps for 25 years and 50 years. Extreme environment aggressiveness.

As expected, high values for the probability of failure are observed for points positioned near the external boundaries. In addition, the probability of failure values decrease faster as these points move from the boundary to the cross-section kernel. It is worth mentioning the huge influence of the environment aggressiveness level on the probability of failure values. Thus, higher probability of failure values are observed as higher is the environment aggressiveness. The probabilities of failure evolve faster at the upper cross-section boundary because at this position the chloride concentration at the surface is higher than at the other boundaries. In addition, the probabilities of failure values decrease near the boundaries in which the flux is assumed as nil, as expected. The results presented in the three last figures show the major importance of designing properly the cover thickness 
taking into account the environment aggressiveness. Moreover, the corrosion time initiation may be improved by utilizing proper schemes that make nil the flux at specific structural boundaries.

Additional analyses were performed to determine, in a detailed mode, the evolution of the probability of failure in particular regions of the T-cross-section shape. Then, internal points were concentrated at specific regions, in spite of the boundary conditions are applied along the entire cross-section boundaries. Three regions were utilized for this purpose: the corner A, the corner $\mathrm{H}$ and the left portion of the slab. 196 internal points were utilized for achieving the map of isoprobability of failure at the corner A. The same map was obtained by 192 internal points in corner H. Finally, the slab region was analysed accounting for 196 internal points. Such points were uniformly distributed along each particular analysed region. The regions dimensions are illustrated in Figure 15, Figure 16 and Figure 17. It is worth mentioning that the additional analyses were performed taking into account solely the normal environment aggressiveness. Moreover, for each region, the probability of failure was assessed considering as structural service life of 25 years, 50 years and 75 years.
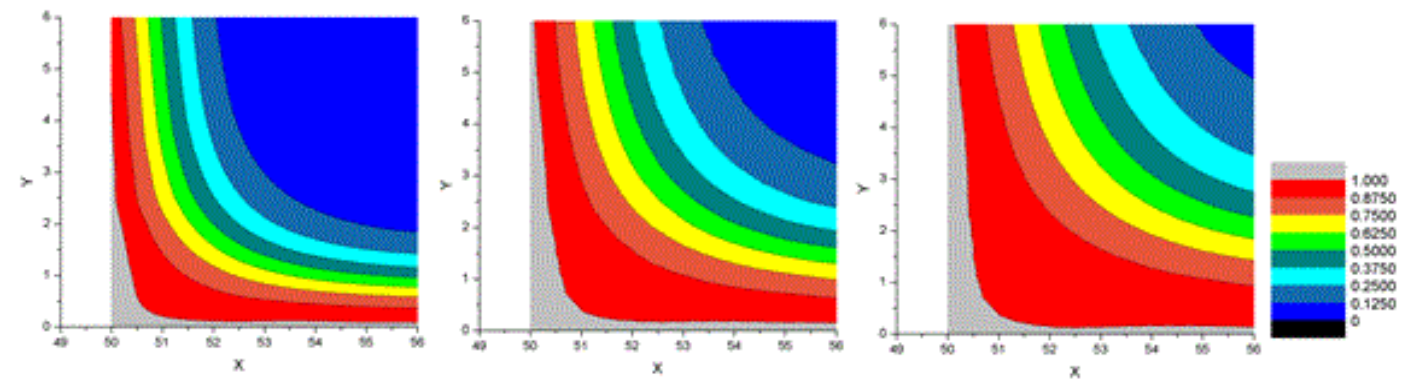

Figure 15 - Isoprobability of failure curves for corner A. Probability of failure values for 25 years, 50 years and 75 years. Dimensions in $\mathrm{cm}$.
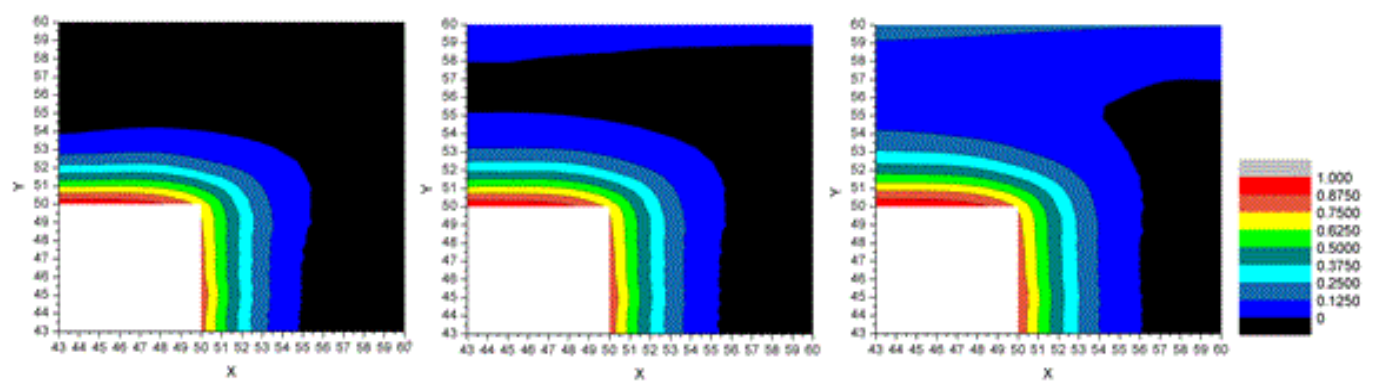

Figure 16 - Isoprobability of failure curves for corner H. Probability of failure values for 25 years, 50 years and 75 years. Dimensions in $\mathrm{cm}$.
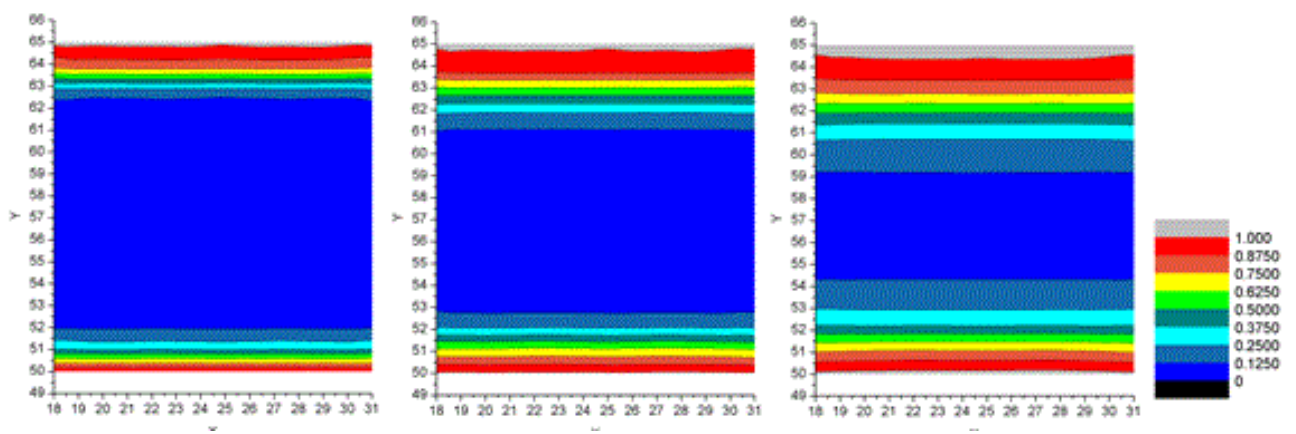

Figure 17 - Isoprobability of failure curves for slab region. Probability of failure values for 25 years, 50 years and 75 years.

Dimensions in $\mathrm{cm}$. 
The last three figures illustrate different evolutions of the probability of failure, although each particular region belong to the same cross-section. Such differences are explained by the boundary conditions and the cross-section geometry, which have major importance into the chloride diffusion evolution inside the material. In addition, these results demonstrate that Fick's approach is not robust in the solution of problems with multidirectional flux condition.

The probabilities of failure grow faster along time for the corner A, Figure 15. Nevertheless, the probabilities of failure values decay faster as the analysed point is far from the boundaries. For the cover thickness from 1.0 to $5.0 \mathrm{~cm}$, the probabilities of failure decay from 0.9737 to 0.0745 at 50 years. This behaviour emphasizes the major importance of adopting fair values for cover thickness, which lead to the adequate durability. Similar behaviour is observed for the corner H, Figure 16. However, in this corner, the growth of the probability of failure is smooth in comparison with corner A. Such behaviour is explained by the slab presence, which smooths the chloride flux distribution at that position. Finally, the probability of failure values grow faster and uniformly at the slab thickness, Figure 17. This behaviour is explained by the bidirectional chloride flux ingress, which occur at upper and lower slab boundaries.

The results presented in this application demonstrate the large influence of the bidirectional chloride flux into the chloride concentration at the material domain. Moreover, the results illustrate the major importance of adopting proper cover thickness values because the probability of failure decay faster along the cover thickness.

\section{CONCLUSIONS}

This study presented a diffusion-probabilistic framework to analyse the corrosion time initiation in concrete structures. The diffusion phenomenon is modelled by the BEM, in which transient potential and flux conditions are accounted. Two-dimensional conditions are assumed. Then, the chloride concentration evolution along time for particular cross-sections are handled. The MCSM was utilized to quantify the uncertainties. The BEM has been marginally utilized in the literature for modelling the chloride ingress. Moreover, the coupling of accurate and robust numerical models for diffusion to probabilistic approaches has been also marginally explored in the literature. Then, these aspects are original in the present study.

The first application demonstrates the robustness of the diffusion BEM model over classical analytical approaches, such as the Fick's law. This application demonstrates that complex diffusion problems are not properly handled by the analytical approach, in spite of the Fick's law is largely utilized for this purpose.

The second and third applications demonstrate the uncertainty quantification process in complex diffusion problems. The evolution of the probability of failure along the cross-section domain is demonstrated. In addition, the results show the importance of designing properly the cover thickness, which enables the adequate structural durability. The cover depth value may be achieved by coupling the proposed framework to optimisation approaches. In this case, the cover depth value may be achieved accounting for a desired safety level, i.e, a probability of failure target.

\section{ACKNOWLEDGEMENTS}

This study was financed in part by the Coordenação de Aperfeiçoamento de Pessoal de Nível Superior - Brasil (CAPES) - Finance Code 001.

\section{REFERENCES}

[1] L. Courard, A. Gillard, A. Darimont, J. M. Bleus, and P. Paquet, "Pathologies of concrete in Saint-Vincent Neo-Byzantine Church and Pauchot reinforced artificial stone," Constr. Build. Mater., vol. 34, pp. 201-210, 2012., http://dx.doi.org/10.1016/j.conbuildmat.2012.02.070.

[2] D. Bru, A. González, F. J. Baeza, and S. Ivorra, "Seismic behavior of 1960's RC buildings exposed to marine environment," Eng. Fail. Anal., vol. 90, pp. 324-340, 2018., http://dx.doi.org/10.1016/j.engfailanal.2018.02.011.

[3] J. R. A. Goncalves, Y. Boluk, and V. Bindiganavile, "Crack growth resistance in fibre reinforced alkali-activated fly ash concrete exposed to extreme temperatures," Mater. Struct., vol. 51, no. 42, pp. 42, 2018., http://dx.doi.org/10.1617/s11527-018-1163-6.

[4] T. Ueda and K. Takewaka, "Performance-based standard specifications for maintenance and repair of concrete structures in Japan," Struct. Eng. Int., vol. 4, no. 4, pp. 359-366, 2007, http://dx.doi.org/10.2749/101686607782359119.

[5] E. A. P. Liberati, C. G. Nogueira, E. D. Leonel, and A. Chateauneuf, "Failure analysis of reinforced concrete structures subjected to chloride penetration and reinforcements corrosion," in Handbook of Materials Failure Analysis with Case Studies from the Chemicals, Concrete and Power Industries, A. S. H. Makhlouf and M. Aliofkhazrae, Eds., Oxford: Butterworth-Heinemann, 2016.

[6] F. Shaikh, "Effect of cracking on corrosion of steel in concrete," Int. J. Concr. Struct. Mater., vol. 12, no. 1, pp. 1-12, 2018, http://dx.doi.org/10.1186/s40069-018-0234-y. 
[7] A. Silva, R. Neves, and J. Brito, "Statistical modelling of carbonation in reinforced concrete," Cement Concr. Compos., vol. 50, pp. 73-81, 2014, http://dx.doi.org/10.1016/j.cemconcomp.2013.12.001.

[8] Y. Zhou, B. Gencturk, K. Willam, and A. Attar, "Carbonation-induced and chloride-induced corrosion in reinforced concrete structures," J. Mater. Civ. Eng., vol. 27, no. 9, pp. 1-17, 2015, http://dx.doi.org/10.1061/(ASCE)MT.1943-5533.0001209.

[9] K. Tuuti, Corrosion of Steel in Concrete Swedish. Stockholm: Cement and Concrete Research Institute, 1982.

[10] X. Shi, N. Xie, K. Fortune, and J. Gong, "Durability of steel reinforced concrete in chloride environments: An overview," Constr. Build. Mater., vol. 30, pp. 125-138, 2012, http://dx.doi.org/10.1016/j.conbuildmat.2011.12.038.

[11] E. A. Liberati, C. G. Nogueira, E. D. Leonel, and A. Chateauneuf, "Nonlinear formulation based on FEM, Mazars damage criterion and Fick's law applied to failure assessment of reinforced concrete structures subjected to chloride ingress and reinforcements corrosion," Eng. Fail. Anal., vol. 46, pp. 247-268, 2014, http://dx.doi.org/10.1016/j.engfailanal.2014.09.006.

[12] D. Chen and S. Mahadevan, "Chloride-induced reinforcement corrosion and concrete cracking simulation," Cement Concr. Compos., vol. 30, no. 3, pp. 227-238, 2008, http://dx.doi.org/10.1016/j.cemconcomp.2006.10.007.

[13] L. Saad, A. Aissani, A. Chateauneuf, and W. Raphael, "Reliability-based optimization of direct and indirect LCC of RC bridge elements under coupled fatigue-corrosion deterioration processes," Eng. Fail. Anal., vol. 59, pp. 570-587, 2016, http://dx.doi.org/10.1016/j.engfailanal.2015.11.006.

[14] T.-B. Tran, E. Bastidas-Arteaga, F. Schoefs, and S. Bonnet, "A Bayesian network framework for statistical characterisation of model parameters from accelerated tests: application to chloride ingress into concrete," Struct. Infrastruct. Eng., vol. 14, no. 5, pp. 580-593, 2018, http://dx.doi.org/10.1080/15732479.2017.1377737.

[15] P. Faustino, C. Chastre, Â. Nunes, and A. Brás, "Lifetime modelling of chloride-induced corrosion in concrete structures with Portland and blended cements," Struct. Infrastruct. Eng., vol. 12, no. 9, pp. 1013-1023, 2016, http://dx.doi.org/10.1080/15732479.2015.1076487.

[16] E. Bastidas-Arteaga and F. Schoefs, "Stochastic improvement of inspection and maintenance of corroding reinforced concrete structures placed in unsaturated environments," Eng. Struct., vol. 41, pp. 50-62, 2012, http://dx.doi.org/10.1016/j.engstruct.2012.03.011.

[17] A. Ben-Fraj, S. Bonnet, and A. Khelidj, "New approach for coupled chloride/moisture transport in non-saturated concrete with and without slag," Constr. Build. Mater., vol. 35, pp. 761-771, 2012, http://dx.doi.org/10.1016/j.conbuildmat.2012.04.106.

[18] P.-T. Nguyen, E. Bastidas-Arteaga, O. Amiri, and C.-P. El Soueidy, "An efficient chloride ingress model for long-term lifetime assessment of reinforced concrete structures under realistic climate and exposure conditions," Int. J. Concr. Struct. Mater., vol. 11, no. 2, pp. 199-213, 2017, http://dx.doi.org/10.1007/s40069-017-0185-8.

[19] M. B. Otieno, H. D. Beushausen, and M. G. Alexander, "Modelling corrosion propagation in reinforced concrete structures - A critical review," Cement Concr. Compos., vol. 33, no. 2, pp. 240-245, 2010, http://dx.doi.org/10.1016/j.cemconcomp.2010.11.002.

[20] D. V. Val, L. Chernin, and M. G. Stewart, "Experimental and numerical investigation of corrosion-induced cover cracking in reinforced concrete structures," J. Struct. Eng., vol. 135, no. 4, pp. 376-385, 2009, http://dx.doi.org/10.1061/(ASCE)07339445(2009)135:4(376).

[21] A. A. Abouhussien and A. A. A. Hassan, "Experimental and empirical time to corrosion of reinforced concrete structures under different curing conditions," Adv. Civ. Eng., vol. 2014, pp. 1-9, 2014., http://dx.doi.org/10.1155/2014/595743.

[22] S. Guzman, J. C. Galvez, and J. M. Sancho, "Cover cracking of reinforced concrete due to rebar corrosion induced by chloride penetration," Cement Concr. Res., vol. 41, no. 8, pp. 893-902, 2011, http://dx.doi.org/10.1016/j.cemconres.2011.04.008.

[23] K. Audenaert, Q. Yuan, and G. De Schutter, "On the time dependency of the chloride migration coefficient in concrete," Constr. Build. Mater., vol. 24, no. 3, pp. 396-402, 2010, http://dx.doi.org/10.1016/j.conbuildmat.2009.07.003.

[24] M. G. Stewart, X. Wang, and M. N. Nguyen, "Climate change impact and risks of concrete infrastructure deterioration," Eng. Struct., vol. 33, no. 4, pp. 1326-1337, 2011, http://dx.doi.org/10.1016/j.engstruct.2011.01.010.

[25] K. A. T. Vu and M. G. Stewart, "Structural reliability of concrete bridges including improved chloride-induced corrosion models," Struct. Saf., vol. 22, no. 4, pp. 313-333, 2000, http://dx.doi.org/10.1016/S0167-4730(00)00018-7.

[26] J. Crank, The Mathematics of Diffusion, 2nd ed. London: Clarendon Press, 1975.

[27] L. Y. Li, J. Xia, and S. S. Lin, "A multi-phase model for predicting the effective diffusion coefficient of chlorides in concrete," Constr. Build. Mater., vol. 26, no. 1, pp. 295-301, 2012, http://dx.doi.org/10.1016/j.conbuildmat.2011.06.024.

[28] Y. Wu and J. Xiao, "The Multiscale Spectral Stochastic Finite Element Method for Chloride Diffusion in Recycled Aggregate Concrete," Int. J. Comput. Methods, vol. 15, no. 1, pp. 1750078, 2018, http://dx.doi.org/10.1142/S0219876217500785.

[29] J. Xiao, J. Ying, and L. Shen, "FEM simulation of chloride diffusion in modeled recycled aggregate concrete," Constr. Build. Mater., vol. 29, pp. 12-23, 2012, http://dx.doi.org/10.1016/j.conbuildmat.2011.08.073.

[30] Y. Zeng, "Modeling of chloride diffusion in hetero-structured concretes by finite element method," Cement Concr. Compos., vol. 29, no. 7, pp. 559-565, 2007, http://dx.doi.org/10.1016/j.cemconcomp.2007.04.003. 
[31] C. Frier and J. D. Sorensen, "Finite element reliability analysis of chloride ingress into reinforced concrete structures," Struct. Infrastruct. Eng., vol. 3, no. 4, pp. 355-366, 2007, http://dx.doi.org/10.1080/15732470600557688.

[32] O. Na, X.-C. Cai, and Y. Xi, "Corrosion prediction with parallel finite element modeling for coupled hygro-chemo transport into concrete under chloride-rich environment," Materials, vol. 10, no. 350, pp. 350, 2017, http://dx.doi.org/10.3390/ma10040350.

[33] H. S. Al-Alaily, A. A. A. Hassan, and A. A. Hussein, "Use of extended finite element method and statistical analysis for modelling the corrosion-induced cracking in reinforced concrete containing metakaolin," Can. J. Civ. Eng., vol. 45, no. 3, pp. 167-178, 2018, http://dx.doi.org/10.1139/cjce-2017-0298.

[34] R. Duddu, "Numerical modeling of corrosion pit propagation using the combined extended finite element and level set method," Comput. Mech., vol. 54, no. 3, pp. 613-627, 2014, http://dx.doi.org/10.1007/s00466-014-1010-8.

[35] L. C. Wrobel, The Boundary Element Method: Applications in Thermos-fluids and Acoustics, vol. 1. New York: John Wiley \& Sons, 2002.

[36] E. D. Leonel and W. S. Venturini, "Non-linear boundary element formulation applied to contact analysis using tangent operator," Eng. Anal. Bound. Elem., vol. 35, no. 12, pp. 1237-1247, 2011, http://dx.doi.org/10.1016/j.enganabound.2011.06.005.

[37] L. F. Yang, Z. Chen, Q. Gao, and J. W. Ju, "Compensation length of two-dimensional chloride diffusion in concrete using a boundary element model," Acta Mech., vol. 224, no. 1, pp. 123-137, 2013, http://dx.doi.org/10.1007/s00707-012-0721-1.

[38] L. Guo, T. Chen, and X.-W. Gao, "Transient meshless boundary element method for prediction of chloride diffusion in concrete with time dependent nonlinear coefficients," Eng. Anal. Bound. Elem., vol. 36, no. 2, pp. 104-111, 2012, http://dx.doi.org/10.1016/j.enganabound.2011.08.005.

[39] J. Warkus, M. Brem, and M. Raupach, "BEM-models for the propagation period of chloride induced reinforcement corrosion," Mater. Corros., vol. 57, no. 8, pp. 636-641, 2006, http://dx.doi.org/10.1002/maco.200603995.

[40] E. Chen and C. K. Y. Leung, "A coupled diffusion-mechanical model with boundary element method to predict concrete cover cracking due to steel corrosion," Corros. Sci., vol. 126, pp. 180-196, 2017, http://dx.doi.org/10.1016/j.corsci.2017.07.001.

[41] V. V. Val and P. A. Trapper, "Probabilistic evaluation of initiation time of chloride-induced corrosion," Reliab. Eng. Syst. Saf., vol. 93, no. 3, pp. 364-372, 2008, http://dx.doi.org/10.1016/j.ress.2006.12.010.

[42] Q. Zhu, L. Jiang, Y. Chen, J. Xu, and L. Mo, "Effect of chloride salt type on chloride binding behavior of concrete," Constr. Build. Mater., vol. 37, pp. 512-527, 2012, http://dx.doi.org/10.1016/j.conbuildmat.2012.07.079.

[43] M.-T. Liang, R. Huang, and H.-Y. Jheng, "Revisited to the relationship between the free and total chloride diffusivity in concrete," $J$. Mar. Sci. Technol., vol. 18, pp. 442-448, 2010.

[44] Y.-M. Sun, M.-T. Liang, and T.-P. Chang, "Time/depth dependent diffusion and chemical reaction model of chloride transportation in concrete," Appl. Math. Model., vol. 36, no. 3, pp. 1114-1122, 2012, http://dx.doi.org/10.1016/j.apm.2011.07.053.

[45] K. Y. Ann, J. H. Ahn, and J. S. Ryou, "The importance of chloride content at the concrete surface in assessing the time to corrosion of steel in concrete structures," Constr. Build. Mater., vol. 23, no. 1, pp. 239-245, 2009, http://dx.doi.org/10.1016/j.conbuildmat.2007.12.014.

[46] S. Zhou, "Analytical model for square root increase of surface chloride concentration and decrease of chloride diffusivity," J. Mater. Civ. Eng., vol. 28, no. 4, pp. 04015181, 2016, http://dx.doi.org/10.1061/(ASCE)MT.1943-5533.0001483.

[47] C. Alonso, M. Castellote, and C. Andrade, "Chloride threshold dependence of pitting potential of reinforcements," Electrochim. Acta, vol. 47, no. 21, pp. 3469-3481, 2002, http://dx.doi.org/10.1016/S0013-4686(02)00283-9.

[48] M. Shekarchi, A. Bonakdar, M. Bakhshi, A. Mirdamadi, and B. Mobasher, "Transport properties in metakaolin blended concrete," Constr. Build. Mater., vol. 24, no. 11, pp. 2217-2223, 2010, http://dx.doi.org/10.1016/j.conbuildmat.2010.04.035.

[49] F. Farmani, B. Bonakdarpour, and A. A. Ramezanianpour, "pH reduction through amendment of cement mortar with silica fume enhances its biological treatment using bacterial carbonate precipitation," Mater. Struct., vol. 48, no. 10, pp. 3205-3215, 2015, http://dx.doi.org/10.1617/s11527-014-0391-7.

[50] F. Han and Z. Zhang, "Hydration, mechanical properties and durability of high-strength concrete under different curing conditions," J. Therm. Anal. Calorim., vol. 132, no. 2, pp. 823-834, 2018, http://dx.doi.org/10.1007/s10973-018-7007-3.

[51] A. Hajibabaee, M. K. Moradllo, A. Behravan, and M. T. Ley, "Quantitative measurements of curing methods for concrete bridge decks," Constr. Build. Mater., vol. 162, pp. 306-313, 2018, http://dx.doi.org/10.1016/j.conbuildmat.2017.12.020.

[52] M. Shakouri, D. Trejo, and P. Gardoni, "A probabilistic framework to justify allowable admixed chloride limits in concrete," Constr. Build. Mater., vol. 139, pp. 490-500, 2017, http://dx.doi.org/10.1016/j.conbuildmat.2017.02.053.

[53] F. Biondini and D. M. Frangopol, "Probabilistic limit analysis and lifetime prediction of concrete structures," Struct. Infrastruct. Eng., vol. 4, no. 5, pp. 399-412, 2008, http://dx.doi.org/10.1080/15732470701270157.

[54] A. Alipour, B. Shafei, and M. S. Shinozuka, "Capacity loss evaluation of reinforced concrete bridges located in extreme chlorideladen environments," Struct. Infrastruct. Eng., vol. 9, pp. 8-27, 2013, http://dx.doi.org/10.1080/15732479.2010.525243.

[55] D. Curran, M. Cross, and B. A. Lewis, “A preliminary analysis of boundary element methods applied to parabolic partial differential equations," in New Developments in Boundary Element Methods, C. A. Brebbia, Ed., Southampton: Comput. Mech. Publ., 1980. 
[56] L. C. Wrobel and C. A. Brebbia, "A formulation of the boundary element method for axisymmetric transient heat conduction," Int. J. Heat Mass Transfer, vol. 24, no. 5, pp. 843-850, 1981, http://dx.doi.org/10.1016/S0017-9310(81)80007-5.

[57] L. C. Wrobel and C. A. Brebbia, "The dual reciprocity boundary element formulation for nonlinear diffusion problems," Comput. Methods Appl. Mech. Eng., vol. 65, no. 2, pp. 147-164, 1987, http://dx.doi.org/10.1016/0045-7825(87)90010-7.

[58] H. S. Carslaw and J. C. Jaeger, Conduction of Heat in Solids, 2nd ed. Oxford: Clarendon Press, 1959.

[59] P. T. Cristensen and M. J. Baker, Structural Reliability Theory and its Applications. Berlin: Springer Science \& Business Media, 2012.

[60] R. McGee, "Modelling of durability performance of tasmanian bridges," in ICASP8 Applications of Statistics and Probability in Civil Engineering, vol. 1, R. E. Melchers and M. G. Stewart, Eds., Rotterdam: Balkema, 1999, pp. 297-306.

[61] D. P. Bentz, J. R. Clifton, and K. A. Snyder, "Predicting service life of chloride-exposed reinforced concrete," Concr. Int., vol. 18, no. 12 , pp. $42-47,1996$.

Author's contributions: GPP implemented the numerical formulations and tested it in several problems. Besides, GPP performed the literature review and wrote this article. EDL proposed the research and supervised the PhD student GPP. EDL wrote this article and handled its review.

Editors: Osvaldo Luís Manzoli, José Luiz Antunes de Oliveira e Sousa, Guilherme Aris Parsekian. 


\section{APPENDIX A: SINGULARITY SUBTRACTION TECHNIQUE EXPRESSIONS}

The singularity subtraction technique is utilized to regularize the kernel $u^{*}$. Then, the integration by parts of kernel $u^{*}$ as a function of time results in:

$U_{I}^{*}(\underline{\xi}, \underline{x})=\int_{t_{0}^{k}}^{t_{f}^{k}} u^{*}\left(\underline{\xi}, \underline{x}, t_{F}, t\right) d t=\frac{1}{4 \pi \kappa}\left\{E_{I}\left[\frac{r^{2}}{4 \kappa\left(t_{F}-t_{0}^{k}\right)}\right]-E_{I}\left[\frac{r^{2}}{4 \kappa\left(t_{F}-t_{f}^{k}\right)}\right]\right\}=\frac{1}{4 \pi \kappa}\left\{E_{I}\left(a_{0}^{k}\right)-E_{I}\left(a_{f}^{k}\right)\right\}$

where $E_{l}$ is the exponential-integral function $E_{l}(z)=\int_{z}^{\infty} \frac{e^{-t}}{t} d t$ and $a_{f}^{k}$ and $a_{0}^{k}$ are as follows:

$$
\begin{aligned}
& a_{f}^{k}=\frac{r^{2}}{4 \kappa\left(t_{F}-t_{f}^{k}\right)} \\
& a_{0}^{k}=\frac{r^{2}}{4 \kappa\left(t_{F}-t_{0}^{k}\right)}
\end{aligned}
$$

The singularity is observed in $U_{k}^{*}$ when $\mathrm{k}=1$, i.e., in the first time step. Moreover, singularity is also observed when the source point approaches to the field point, i.e., when $r \rightarrow 0$. Thus, when $\mathrm{k}=1$, Equation A.1 becomes:

$$
U_{l}^{*}(\underline{\xi}, \underline{x})=\frac{1}{4 \pi \kappa}\left[E_{l}\left(a_{0}^{l}\right)-E_{l}\left(a_{f}^{l}\right)\right]
$$

The variables $a_{f}^{k}$ and $a_{0}^{k}$ always assume non-negative values because $\kappa>0, r \geq 0$ and $t_{F} \geq t_{f}^{k}>t_{0}^{k}$. In Equation A.2, when $r$ is nil and $t_{f}^{l} \rightarrow t_{F}, a_{f}^{l} \rightarrow+\infty$. Thus, the exponential-integral function is evaluated at $+\infty$, which results in a nil value. In Equation A.3 when $\mathrm{r}$ is nil, $a_{0}^{l} \rightarrow 0$, because the denominator $\left(t_{F}-t_{0}^{l}\right)$ is always greater than zero $\left(t_{F} \geq t_{f}^{l}>t_{0}^{l}\right)$. Thus, the exponential-integral function has nil, which results in a singularity as follows:

$U_{1}^{*}(\underline{\xi}, \underline{x})=\frac{1}{4 \pi \kappa}\left[E_{l}(0)-E_{l}(+\infty)\right]=\frac{1}{4 \pi \kappa}\left[E_{l}(0)\right]$

The singularity that arises in this equation is logarithmic for distinct intervals of the exponential-integral function argument, $0 \leq z \leq 1$ and $1<z<\infty$. Thus, the kernel containing $u^{*}$ can be regularized by the following equation:

$$
\int_{\Gamma_{j}} U_{I}^{*}(\underline{\xi}, \underline{x}) d \Gamma_{j}=\frac{1}{4 \pi \kappa} \int_{\Gamma_{j}}\left[E_{l}\left(a_{0}^{I}\right)-\ln \left(a_{0}^{l^{*}}\right)\right] d \Gamma_{j}+\frac{1}{4 \pi \kappa} \int_{\Gamma_{j}} \ln \left(a_{0}^{l *}\right) d \Gamma_{j}
$$

Let $\xi_{0}$ be the dimensionless coordinate of the source point, $\xi$ the dimensionless coordinate of the field point, $x_{i}$ the real coordinate of a given point, $\phi$ the shape function, $\phi_{, i}$ the shape function derivative and being the Jacobian given by $J=\sqrt{\left[\phi_{, i}\left(\xi_{0}\right) x_{i}\right]^{2}}$, the real distance $r$ between the source and the field points is calculated as follows:

$$
r=r^{*}=|J| \varepsilon=|J|\left|\xi-\xi_{0}\right|
$$


where $\varepsilon=\left|\xi-\xi_{0}\right|$ is the dimensionless distance between the source and field points. Substituting $d \Gamma=J d \xi$ in Equation A.6 gives:

$\int_{\Gamma_{j}} U_{l}^{*}(\underline{\xi}, \underline{x}) d \Gamma_{j}=\frac{1}{4 \pi \kappa} \int_{-1}^{l} E_{l}\left(a_{0}^{l}\right) \phi(\xi) J(\xi) d \xi-\frac{1}{4 \pi \kappa} \int_{-1}^{l} \ln \left(a_{0}^{l^{*}}\right) \phi\left(\xi_{0}\right) J\left(\xi_{0}\right) d \xi+\frac{1}{4 \pi \kappa} \int_{-1}^{l} \ln \left(a_{0}^{l^{*}}\right) \phi\left(\xi_{0}\right) J\left(\xi_{0}\right) d \xi$

where:

$a_{0}^{l^{*}}=\frac{\left(r^{*}\right)^{2}}{4 \kappa\left(t_{F}-t_{0}^{l}\right)}=\frac{\left(\left|J\left(\xi_{0}\right)\right||\varepsilon|\right)^{2}}{4 \kappa\left(t_{F}-t_{0}^{l}\right)}$

In Equation A.8, the first two integrals on the right side are bounded and no longer singular. Then, they are numerically evaluated by the Gauss-Legendre quadrature. The last integral is evaluated analytically, being called integral $I$ :

$I=\frac{1}{4 \pi \kappa} \int_{-1}^{l} \ln \left(a_{0}^{I^{*}}\right) \phi\left(\xi_{0}\right) J\left(\xi_{0}\right) d \xi$

The change of the integration domain from $d \xi$ to $d \varepsilon$ and consequently the integration intervals, gives:

$I=\frac{1}{4 \pi \kappa} \int_{-I-\xi_{0}}^{I-\xi_{0}} \ln \left[\frac{\left(\left|J\left(\xi_{0}\right)\right||\varepsilon|\right)^{2}}{4 \kappa\left(t_{F}-t_{0}^{I}\right)}\right] \phi\left(\xi_{0}\right) J\left(\xi_{0}\right) d \varepsilon$

For simplicity, considering $t_{0}^{l}=0$, one obtains:

$I=\frac{1}{4 \pi \kappa} \int_{-I-\xi_{0}}^{1-\xi_{0}} 2 \ln \left(\left|J\left(\xi_{0}\right)\right||\varepsilon|\right) \phi\left(\xi_{0}\right) J\left(\xi_{0}\right) d \varepsilon-\frac{1}{4 \pi \kappa} \int_{-I-\xi_{0}}^{1-\xi_{0}} \ln \left(4 \kappa t_{F}\right) \phi\left(\xi_{0}\right) J\left(\xi_{0}\right) d \varepsilon$

Because of the singular kernel present in Equation A.12, the integral must be evaluated in the Cauchy principal $(\mathrm{CPV})$ sense. Then:

$C P V=\lim _{\varepsilon \rightarrow 0}\left\{\frac{1}{4 \pi \kappa}+\frac{1}{4 \pi \kappa} \int_{+\varepsilon}^{1-\xi_{0}} 2 \ln \left(\left|J\left(\xi_{0}\right)\right||\varepsilon|\right) \phi\left(\xi_{0}\right) J\left(\xi_{0}\right) d \varepsilon-\frac{1}{4 \pi \kappa} \int_{-1-\xi_{0}}^{-\varepsilon} \ln \left(4 \kappa t_{F}\right) \phi\left(\xi_{0}\right) J\left(\xi_{0}\right) d \varepsilon-\frac{1}{4 \pi \kappa} \int_{+\varepsilon}^{1-\xi_{0}} \ln \left(4 \kappa t_{F}\right) \phi\left(\xi_{0}\right) J\left(\xi_{0}\right) d \varepsilon\right\} \rightarrow$

$C P V=\lim _{\varepsilon \rightarrow 0}\left\{\frac{1}{4 \pi \kappa} \phi\left(\xi_{0}\right) J\left(\xi_{0}\right)\left[\int_{-1-\xi_{0}}^{-\varepsilon} 2 \ln \left(\left|J\left(\xi_{0}\right)\right||\varepsilon|\right) d \varepsilon+\int_{+\varepsilon}^{1-\xi_{0}} 2 \ln \left(\left|J\left(\xi_{0}\right)\right||\varepsilon|\right) d \varepsilon-\int_{-1-\xi_{0}}^{-\varepsilon} \ln \left(4 \kappa t_{F}\right) \phi\left(\xi_{0}\right) J\left(\xi_{0}\right) d \varepsilon-\int_{+\varepsilon}^{1-\xi_{0}} \ln \left(4 \kappa t_{F}\right) d \varepsilon\right]\right\}$

To evaluate the terms of Equation A.13 properly, they are written in separated form, from $I_{1}$ to $I_{4}$ as follows:

$C P V=\lim _{\varepsilon \rightarrow 0}\left\{\frac{1}{4 \pi \kappa} \phi\left(\xi_{0}\right) J\left(\xi_{0}\right)\left[I_{1}+I_{2}-\left(I_{3}+I_{4}\right)\right]\right\}$ 
Thus, evaluating $I_{l}$ one has:

$I_{1}=2\left[\varepsilon \ln \left(\left|J\left(\xi_{0}\right) \varepsilon\right|\right)\right]_{-1-\xi_{0}}^{-\varepsilon}=2\left\{-\varepsilon \ln \left(\left|J\left(\xi_{0}\right) \varepsilon\right|\right)+\varepsilon-\left[\left(-1-\xi_{0}\right) \ln \left(\left|J\left(\xi_{0}\right)\left(-1-\xi_{0}\right)\right|\right)+1+\xi_{0}\right]\right\}$

Thus, evaluating $I_{2}$ one has:

$I_{2}=2\left[\varepsilon \ln \left(\left|J\left(\xi_{0}\right) \varepsilon\right|\right)\right]_{\varepsilon}^{1-\xi_{0}}=2\left\{\left(1-\xi_{0}\right) \ln \left(\left|J\left(\xi_{0}\right)\left(1-\xi_{0}\right)\right|\right)-1+\xi_{0}-\left[\varepsilon \ln \left(\left|J\left(\xi_{0}\right) \varepsilon\right|\right)-\varepsilon\right]\right\}$

Then, evaluating $I_{3}$ one has:

$I_{3}=\ln \left(4 \kappa t_{F}\right)\left[-\varepsilon+1+\xi_{0}\right]$

Then, evaluating $I_{4}$ one has:

$I_{4}=\ln \left(4 \kappa t_{F}\right)\left[1-\xi_{0}-\varepsilon\right]$

Adding ${ }^{I_{1}}$ and ${ }^{I_{2}}$ one obtains:

$I_{1}+I_{2}=2\left\{-\varepsilon \ln \left(\left|J\left(\xi_{0}\right) \varepsilon\right|\right)+\varepsilon+\left(1+\xi_{0}\right) \ln \left(\left|J\left(\xi_{0}\right)\left(-1-\xi_{0}\right)\right|\right)-1-\xi_{0}+\left(1-\xi_{0}\right) \ln \left(\left|J\left(\xi_{0}\right)\left(1-\xi_{0}\right)\right|\right)-1+\xi_{0}-\varepsilon \ln \left(\left|J\left(\xi_{0}\right) \varepsilon\right|\right)+\varepsilon\right\} \rightarrow$

$I_{1}+I_{2}=2\left\{-2 \varepsilon \ln \left(\left|J\left(\xi_{0}\right) \varepsilon\right|\right)+2 \varepsilon-2+\left(1+\xi_{0}\right) \ln \left(\left|J\left(\xi_{0}\right)\left(-1-\xi_{0}\right)\right|\right)+\left(1-\xi_{0}\right) \ln \left(\left|J\left(\xi_{0}\right)\left(1-\xi_{0}\right)\right|\right)\right\}$

Adding ${ }^{I_{3}}$ and $I_{4}$ one obtains:

$I_{3}+I_{4}=\ln \left(4 \kappa t_{F}\right)\left[-\varepsilon+1+\xi_{0}+1-\xi_{0}-\varepsilon\right]=\ln \left(4 \kappa t_{F}\right)[-2 \varepsilon+2]$

By applying the L'Hôpital's theorem one obtains:

$\lim _{\varepsilon \rightarrow 0}\left\{\varepsilon \ln \left(J\left(\xi_{0}\right) \varepsilon\right)\right\}=0$

Therefore, the limit of Equation A.14 is achieved as follows:

$C P V=\frac{1}{4 \pi \kappa} \phi\left(\xi_{0}\right) J\left(\xi_{0}\right)\left\{-4+2\left(1+\xi_{0}\right) \ln \left(\left|J\left(\xi_{0}\right)\left(-1-\xi_{0}\right)\right|\right)+2\left(1-\xi_{0}\right) \ln \left(\left|J\left(\xi_{0}\right)\left(1-\xi_{0}\right)\right|\right)-2 \ln \left(4 \kappa t_{F}\right)\right\}$

\section{Consequently:}

$C P V=\frac{1}{2 \pi \kappa} \phi\left(\xi_{0}\right) J\left(\xi_{0}\right)\left\{-2+\left(1+\xi_{0}\right) \ln \left(\left|J\left(\xi_{0}\right)\left(-1-\xi_{0}\right)\right|\right)+\left(1-\xi_{0}\right) \ln \left(\left|J\left(\xi_{0}\right)\left(1-\xi_{0}\right)\right|\right)-\ln \left(4 \kappa t_{F}\right)\right\}$ 
It is worth mentioning that Equation A.23 is valid for discontinuous elements, i.e., when the source points are not positioned at the element ends $\xi_{0}= \pm 1$. When continuous elements are utilized, the finite part of Equation A.23) is evaluated, leading to the following:

$$
C P V=\frac{1}{2 \pi \kappa} \phi\left(\xi_{0}\right) J\left(\xi_{0}\right)\left\{-2+2 \ln \left(\left|2 J\left(\xi_{0}\right)\right|\right)-\ln \left(4 \kappa t_{F}\right)\right\}
$$

\section{APPENDIX B: CONVERGENCE ANALYSIS FOR MONTE CARLO SIMULATIONS}

This appendix presents the convergence analysis for the probabilistic modelling. Particularly, the application 3 is accounted, which is the complex case handled in this study. Figures 18, 19 and 20 illustrate the convergence analysis. These figures demonstrate that the range sampling of 10,000 is sufficient for describing the assessment space.

Because the application 3 is complex than application 2, the same range of sampling is sufficient for describing the assessment space of the latter application.

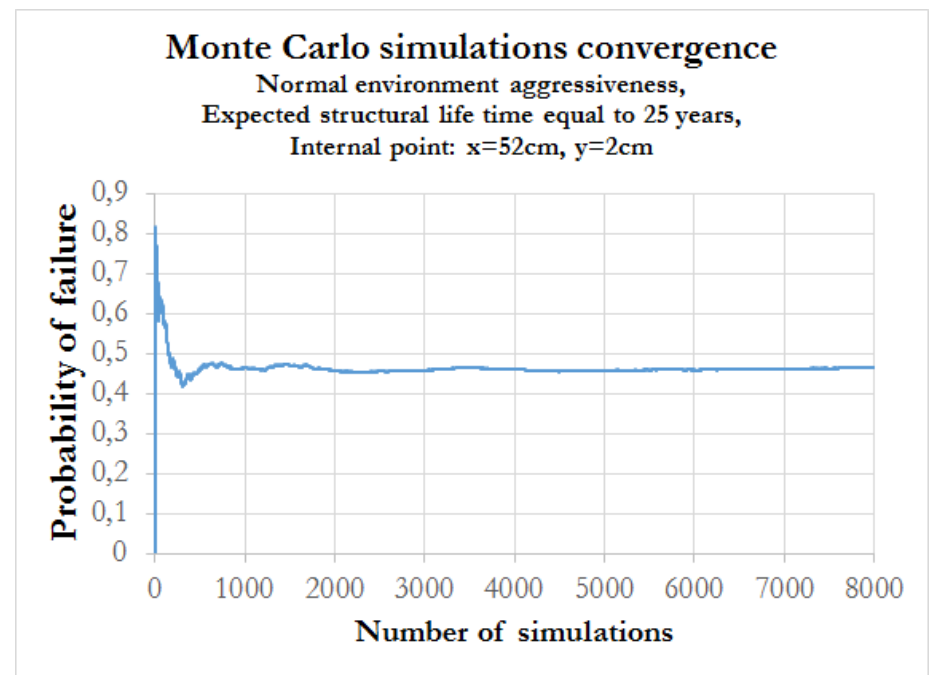

Figure 18 - Convergence analysis for $\mathrm{x}=52 \mathrm{~cm}, \mathrm{y}=2 \mathrm{~cm}$ and $\mathrm{t}=25$ years.

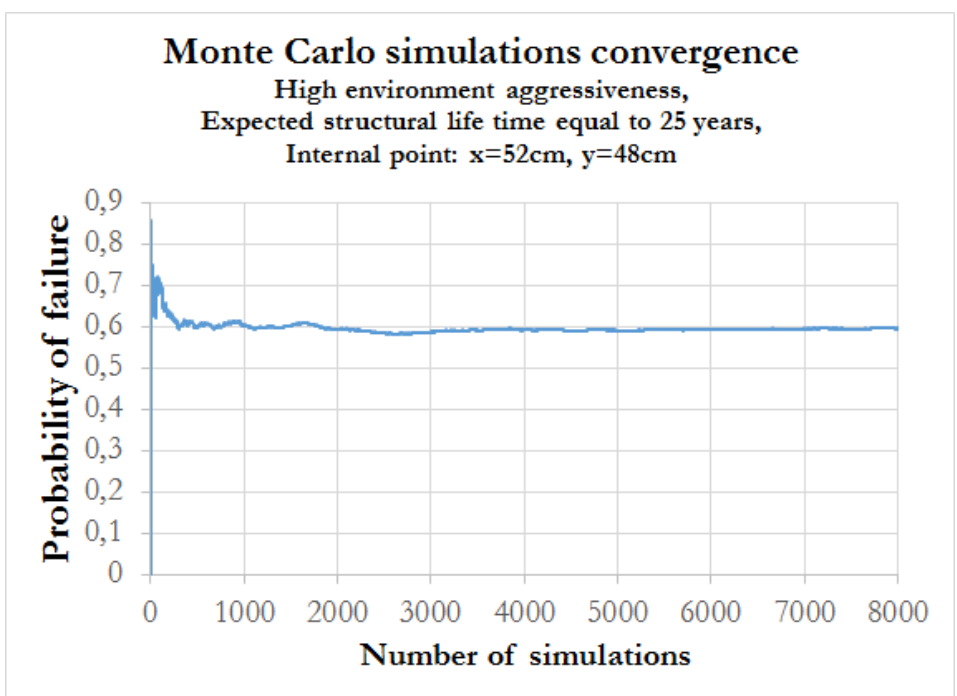

Figure 19 - Convergence analysis for $\mathrm{x}=52 \mathrm{~cm}, \mathrm{y}=48 \mathrm{~cm}$ and $\mathrm{t}=25$ years. 


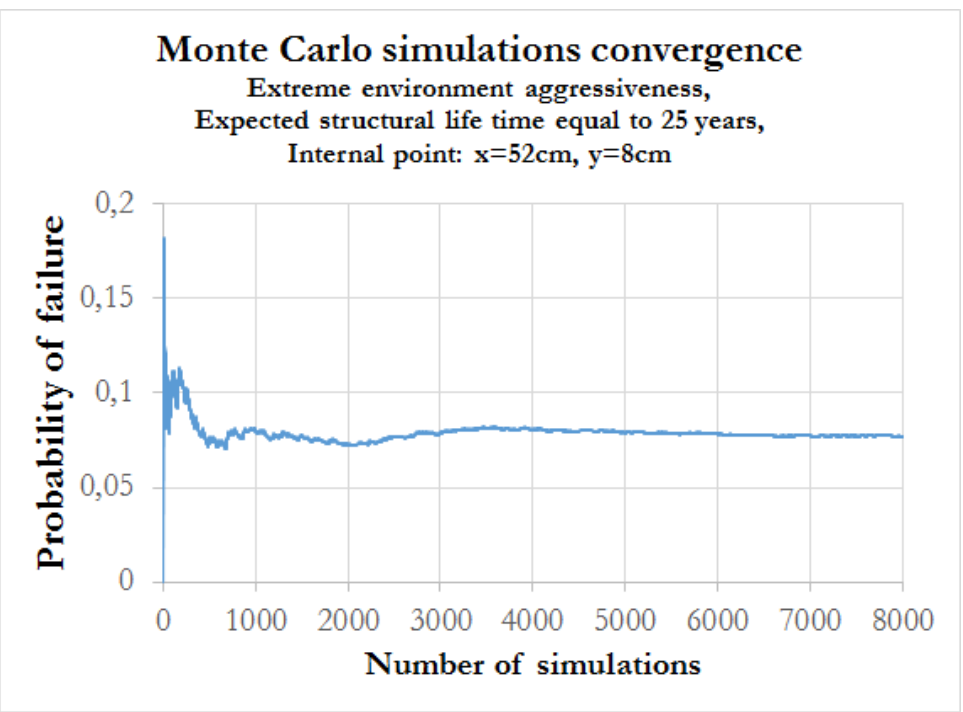

Figure 20 - Convergence analysis for $\mathrm{x}=52 \mathrm{~cm}, \mathrm{y}=8 \mathrm{~cm}$ and $\mathrm{t}=25$ years. 